\title{
Review of Intra-Arterial Therapies for Colorectal Cancer Liver Metastasis
}

\author{
Justin Kwan * and Uei Pua
}

Citation: Kwan, J.; Pua, U. Review of Intra-Arterial Therapies for Colorectal Cancer Liver Metastasis. Cancers 2021, 13, 1371. https://doi.org/10.3390/ cancers13061371

Academic Editor: Constantinos T. Sofocleous

Received: 4 February 2021

Accepted: 15 March 2021

Published: 18 March 2021

Publisher's Note: MDPI stays neutral with regard to jurisdictional claims in published maps and institutional affiliations.

Copyright: (c) 2021 by the authors. Licensee MDPI, Basel, Switzerland. This article is an open access article distributed under the terms and conditions of the Creative Commons Attribution (CC BY) license (https:/ / creativecommons.org/licenses/by/ $4.0 /)$.
Department of Vascular and Interventional Radiology, Tan Tock Seng Hospital, Singapore 388403, Singapore; pua_uei@ttsh.com.sg

* Correspondence: Justin_kwan@ttsh.com.sg

Simple Summary: Colorectal cancer liver metastasis occurs in more than $50 \%$ of patients with colorectal cancer and is thought to be the most common cause of death from this cancer. The mainstay of treatment for inoperable liver metastasis has been combination systemic chemotherapy with or without the addition of biological targeted therapy with a goal for disease downstaging, for potential curative resection, or more frequently, for disease control. For patients with dominant liver metastatic disease or limited extrahepatic disease, liver-directed intra-arterial therapies including hepatic arterial chemotherapy infusion, chemoembolization and radioembolization are alternative treatment strategies that have shown promising results, most commonly in the salvage setting in patients with chemo-refractory disease. In recent years, their role in the first-line setting in conjunction with concurrent systemic chemotherapy has also been explored. This review aims to provide an update on the current evidence regarding liver-directed intra-arterial treatment strategies and to discuss potential trends for the future.

Abstract: The liver is frequently the most common site of metastasis in patients with colorectal cancer, occurring in more than $50 \%$ of patients. While surgical resection remains the only potential curative option, it is only eligible in $15-20 \%$ of patients at presentation. In the past two decades, major advances in modern chemotherapy and personalized biological agents have improved overall survival in patients with unresectable liver metastasis. For patients with dominant liver metastatic disease or limited extrahepatic disease, liver-directed intra-arterial therapies such as hepatic arterial chemotherapy infusion, chemoembolization and radioembolization are treatment strategies which are increasingly being considered to improve local tumor response and to reduce systemic side effects. Currently, these therapies are mostly used in the salvage setting in patients with chemo-refractory disease. However, their use in the first-line setting in conjunction with systemic chemotherapy as well as to a lesser degree, in a neoadjuvant setting, for downstaging to resection have also been investigated. Furthermore, some clinicians have considered these therapies as a temporizing tool for local disease control in patients undergoing a chemotherapy 'holiday' or acting as a bridge in patients between different lines of systemic treatment. This review aims to provide an update on the current evidence regarding liver-directed intra-arterial treatment strategies and to discuss potential trends for the future.

Keywords: colorectal liver metastasis; liver-directed intra-arterial therapy; hepatic arterial infusion therapy; trans-arterial chemoembolization; radioembolization

\section{Introduction}

Colorectal cancer (CRC) is the fourth most common cancer amongst men and women in the United States. In 2019, there were an estimated 145,600 new CRC cases in the US, with 51,020 deaths resulting from the disease [1]. Despite excellent advances in the field through a combination of early detection from screening, lifestyle prevention and improved systemic and loco-regional treatment strategies, approximately $20 \%$ of patients 
will have colorectal liver metastasis (CRLM) at first presentation [1], and more than 50\% of patients will eventually develop CRLM during the course of their disease [2]. Notably, the liver is the most common site for metastasis from CRC, occurring in more than $70 \%$ of patients with metastatic disease, and is the most frequent cause of death related to this cancer [3]. Surgical resection of CRLM is the only potentially curative option and is considered whenever possible, demonstrating overall 5-year survival of $25-40 \%$ [4] compared to patients who are either untreated or undergo systemic chemotherapy alone, whom rarely survive past 5 years [5]. Unfortunately, only $20 \%$ of patients at presentation are considered to be potential surgical candidates for CRLM resection [6,7]. Further, patients who undergo a successful hepatic metastectomy have a fair probability of developing intrahepatic metastasis recurrence (approximately $30 \%$ ), with a significant proportion of the recurrences developing within the first 2 years after resection [8].

For the majority of patients with unresectable CRLM, the mainstay of treatment is a doublet or triplet combination of systemic chemotherapy comprising of fluropyrimides (e.g., 5-Flurouracil (5-FU)), leucovorin and/or either oxaliplatin (FOLFOX) or irinotecan (FOLFIRI), with or without targeted therapies (e.g., anti-epidermal growth factor receptor (EGFR) for Kirsten rat sarcoma (KRAS) wild-type tumors and anti-vascular endothelial growth factor (VEGF) agents). These combination treatments have been associated with a significant improvement in overall survival (OS), reaching a median duration of over 30 months in certain studies [9]. Triplet chemotherapy regimens have been investigated (FOLFOXFIRI) with improved median progression-free survival (PFS) times and response rates (RR) at the expense of increased reports of systemic toxicity [10].

Over the past few decades, the field of interventional oncology has established its position as one of the four pillars of cancer patient care alongside surgical, medical and radiation oncology, offering clinicians an ever-growing armamentarium of local and locoregional therapies to improve local disease control, prolong overall survival and palliate symptoms. This especially holds true in patients who progress despite systemic therapy. Liver-directed intra-arterial therapies (IAT), such as hepatic arterial infusion chemotherapy (HAIC), trans-arterial chemoembolization (TACE) and selective internal radiation therapy (SIRT), are inherently attractive options for patients with liver-only or liver-dominant metastatic disease due to the dual blood supply (70\% portal and 30\% arterial) to the liver parenchyma and the almost exclusive hepatic arterial supply to CRLM [11,12]. Thus, this allows preferential delivery of therapeutic agents directly to the tumor whilst minimizing significant hepatic and systemic toxicity. IATs have traditionally been considered in the salvage setting in patients with chemo-refractory disease, although in recent years, much research has investigated their use both in an adjuvant setting (for HAIC) as well as in a first-line setting in conjunction with systemic chemotherapy.

Current National Comprehensive Cancer Network (NCCN) and European Society of Medical Oncology (ESMO) guidelines recommend IATs in highly selected chemo-refractory patients with predominant liver metastatic disease $[13,14]$. ESMO guidelines also further stipulate that there may be a possible role for TACE or SIRT in a neoadjuvant and adjuvant setting, although this particular application should be limited to clinical trials at present. A note is made that in the case of SIRT, the available evidence leading to its inclusion in these guidelines are modest at best, with none of the randomized studies conferring a significant OS advantage when compared to the current standard of care $[15,16]$. Interestingly, Yytirum-90 (Y-90) SIRT has also garnered evidence in the latest NCCN guidelines (2A recommendation) to support contralateral liver lobe hypertrophy in patients who are being considered for resection with insufficient remnant liver volume [17]. This recent change is a clear indication of the potential growth for the role of IAT, not only limited to patients with unresectable disease. As there is an ever-growing body of evidence from the literature, their role in this treatment paradigm remains to be defined, especially with much recent emphasis placed on tumor biology, both for prognostication purposes and improving treatment outcomes. The focus of this review is to provide an update on the 
current evidence on each of the treatment modalities as well as to discuss potential trends for the future.

\section{Hepatic Arterial Infusion Chemotherapy (HAIC)}

HAIC has been available since the late 1980s and has been extensively studied in patients with CRLM. As the name implies, chemotherapeutic agents are infused directly into the hepatic artery via a surgically or percutaneously implanted catheter connected to a hepatic arterial port/external pump. This consequently allows preferential drug delivery directly to CRLM with relative sparing of the background liver parenchyma [12] and allows drugs to circumvent the first-pass effects of hepatic excretion, thus exposing tumor cells to a significantly higher concentration of chemotherapy as well as limiting systemic toxic effects. To put this in perspective, intra-tumoral concentrations of flurodeoxyuridine (FUDR), a 5-FU derivative, which is the most commonly used agent in the United States, can be up to 400 -fold greater when compared to systemic infusion due to its high (95\%) first-pass hepatic excretion [18]. Other agents such as oxaliplatin and irinotecan, already used in the first and second-line systemic treatment for unresectable CRLM, have also been trialed in HAIC, mostly in Europe and Asia, despite having a less favorable pharmacokinetic profile when compared to FUDR, and a different toxicity profile [19-22]. One fundamental principle of HAIC is that the hepatic artery has to be skeletonized such that the whole liver is supplied by a single artery. This usually requires surgical ligation (in the setting of surgical port placement) or permanent, proximal embolization (in the setting of percutaneous port placement) of the gastroduodenal artery (GDA) and the right gastric artery to prevent non-target mucosal injury, as well as toxicity due to extrahepatic drug perfusion $[23,24]$. The tip of the infusion catheter is usually parked in the gastroduodenal artery with a perfusion side hole in the hepatic artery proper to prevent dislodgement and to enable bilobar hepatic infusion [23]. If the catheter cannot be placed in the GDA, either for anatomical reasons or from previous ligation, the catheter is placed in a peripheral side branch of the hepatic artery. Whilst HAIC therapy has its appeals, initiation of therapy as well as administration can be complex. As such, it is likely that this treatment modality will only be offered at high-volume surgical oncology institutions with an established multidisciplinary infrastructure $[25,26]$.

\subsection{Evidence for HAIC in Unresectable CRLM}

In patients with unresectable CRLM, the effectiveness of HAIC with combination systemic therapy has shown to improve local RR as well as OS. For this article, RR is based on the response evaluation criteria in solid tumors (RECIST) unless otherwise stated. The pertinent evidence on HAIC in this review is summarized in Table 1. In 2001, Kemeny et al. [27] conducted a Phase I study investigating HAIC with FUDR/dexamethasone with systemic irinotecan in 46 patients previously treated for unresectable CRLM (41\% of the study cohort had previously been treated with two lines of systemic treatment) and showed a high RR of 74\% (according to the World Health Organization (WHO) response criteria), with a median OS of 20 months. In a subsequent trial in 2005 [28], the same group conducted a separate phase I study in 36 patients, examining HAIC with FUDR/dexamethasone combined with systemic oxaliplatin and either irinotecan ( 21 patients) or fluorouracil/leucovorin (15 patients). Notably, in this cohort, almost $90 \%$ of patients were previously treated with systemic chemotherapy. For the irinotecan group, RR was observed in $90 \%$ (WHO criteria) of patients with median OS of 36 months, and for the fluorouracil/leucovorin group, RR was $87 \%$ with median OS of 22 months. Interestingly, 7 patients $(19 \%)$ in the irinotecan group had a good enough response to be down-staged for liver resection, probably contributing to the longer OS in this group. 
Table 1. Selected prospective trials and retrospective studies for Hepatic Arterial Infusion Chemotherapy (HAIC) with systemic chemotherapy.

\begin{tabular}{|c|c|c|c|c|c|c|c|c|c|c|c|}
\hline \multirow{2}{*}{$\begin{array}{c}\text { Author and } \\
\text { Year Published }\end{array}$} & \multirow{2}{*}{ Study Design } & \multirow{2}{*}{$\begin{array}{l}\text { No. of } \\
\text { Patients }\end{array}$} & \multirow[t]{2}{*}{ Study Arm } & \multicolumn{4}{|c|}{$\begin{array}{l}\text { Prior Lines of Systemic Chemotherapy, } \\
\text { No. of Prior Lines: No. of Patients }\end{array}$} & \multirow{2}{*}{ RR, \% } & \multirow{2}{*}{ PFS, mo } & \multirow{2}{*}{ OS, mo } & \multirow{2}{*}{$\begin{array}{l}\text { Conversion to } \\
\text { Resection, \% }\end{array}$} \\
\hline & & & & None & 1 & 2 & 3 or More & & & & \\
\hline Kemeny 2005 [28] & $\begin{array}{l}\text { Prospective, } \\
\text { P-I }\end{array}$ & 36 & $\begin{array}{l}\text { Arm 1: HAI FUDR + } \\
\text { SYS OXA/IRI } \\
\text { Arm 2: HAI FUDR + } \\
\text { SYS OXA/FU/LV }\end{array}$ & 4 & 32 & - & - & $\begin{array}{l}90 \\
86\end{array}$ & $\begin{array}{l}16.4 \\
9.4\end{array}$ & $\begin{array}{c}35.8 \\
22\end{array}$ & $19^{a}$ \\
\hline Kemeny 2009 [29] & $\begin{array}{l}\text { Prospective, } \\
\text { P-I }\end{array}$ & 49 & $\begin{array}{l}\text { HAI FUDR/Dex + SYS } \\
\text { OXA/IRI }\end{array}$ & 23 & & 26 & & 92 & NR & 39.8 & $47^{\mathrm{b}}$ \\
\hline Lévi 2011 [31] & Retrospective & 56 & $\begin{array}{c}\text { Chronomodulated } \\
\text { HAI combination of } \\
\text { 5-FU/IRI/OXA + } \\
\text { SYS CET }\end{array}$ & - & 8 & 12 & 36 & 32.1 & 4.6 & 13.7 & 11 \\
\hline Lévi 201630 [32] & $\begin{array}{l}\text { Prospective, } \\
\text { P-II }\end{array}$ & 64 & $\begin{array}{l}\text { HAI 5-FU/IRI/OXA + } \\
\text { SYS CET }\end{array}$ & - & 28 & & 36 & 41 & 9.3 & 25.7 & 30 \\
\hline Cercek 2016 [33] & Retrospective & 110 & $\begin{array}{l}\text { HAI FUDR + BEST } \\
\text { SYS chemotherapy e }\end{array}$ & & & & $110^{\mathrm{f}}$ & 35 & 5 & 16.3 & NR \\
\hline
\end{tabular}

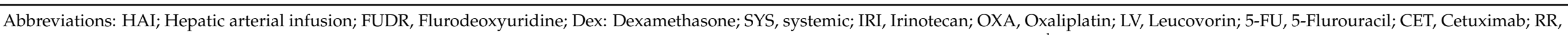

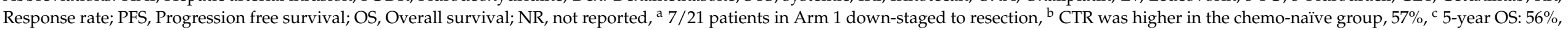

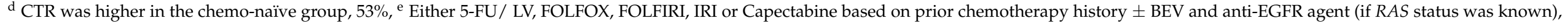

${ }^{\mathrm{f}}$ All patients progressed on at least 3 lines of prior systemic chemotherapy (5-FU, OXA, IRI), ${ }^{\mathrm{g}}$ Either OXA/IRI or 5-FU/ LV/IRI based on prior chemotherapy history $\pm \mathrm{BEV}$. 
Promising data obtained from these early trials gave rise to further emphasis on the potential to convert initially unresectable CRLM to resectable/ablatable disease, essentially in a neoadjuvant setting. In a Phase I trial investigating conversion to resectability rates (CTR) [29], forty-nine patients with unresectable CRLM (53\% previously treated with systemic chemotherapy) were treated with HAIC with FUDR/dexamethasone plus systemic oxaliplatin and irinotecan. Overall RR was $92 \%$ (WHO criteria) and CTR rate was $47 \%$ ( $57 \%$ in patients who were chemotherapy-naïve). On examining the patients that underwent resection, $73 \%$ patients had more than 5 lesions, $98 \%$ had bilobar disease and $65 \%$ had more than $50 \%$ of the liver involved-none of these variables reflecting extensive tumor burden were significantly associated with the probability of resection. The results of this study were further validated in a prospective phase II trial evaluating the long-term results and curative potential for patients treated with combination HAIC and systemic chemotherapy [34]. In this study of 64 patients (67\% previously treated with systemic chemotherapy) with a median follow-up time of 81 months, thirty-three patients (52\%) were converted to resection, doubling the historical rate, with a median PFS and OS of 13 and 38 months, respectively. Further, patients who underwent CRLM resection had a significantly longer 5 -year OS of $63 \%$ compared to $13 \%$ in unresected patients. In a similar prospective study by Goere et al. [30] of 87 patients ( $79 \%$ previously treated with systemic chemotherapy) with unresectable CRLM treated with oxaliplatin HAIC and systemic 5-FU and leucovorin, the CTR rate was $26 \%$. In patients who underwent resection, median OS of 41.7 months and 5-year OS of 56\% were achieved. This study also demonstrated that CTR rates were significantly higher in patients who received HAIC in the first-line setting (53\%, 10/19 patients) compared to those that received HAIC after failure of prior systemic chemotherapy $(19 \%, 13 / 68$ patients). In a European phase II multi-center trial (OPTILIV) [32], sixty-six patients (28 patients enrolled as second-line treatment and $36 \mathrm{pa}-$ tients enrolled as third / fourth-line treatment) were treated with a triplet combination of HAIC comprising of irinotecan, oxaliplatin and 5-FU with intravenous cetuximab. Patients had a median of 10 liver metastases involving a median of 6 segments. CTR was $30 \%$ with a median OS of 25.7 months in all patients. In a separate analysis on the OPTILIV trial [35], a RR of $63 \%$ was achieved in patients on second-line treatment and a RR of $38 \%$ and OS of 15.2 months in patients on third/fourth-line treatment.

The effectiveness of HAIC in heavily pre-treated patients is supported in several studies. In a retrospective review [33] of 110 patients with disease progression failing at least 3 prior standard systemic therapies, HAIC with concurrent systemic treatment showed a RR of $35 \%$ and an average OS of 16.3 months (20 months in patients with liver metastasis only and 11.4 months in patients with low-volume extrahepatic disease), which is significantly higher when compared to historical data in patients with chemo-refractory disease. In a separate study by Lévi et al. [31], fifty-six patients who had progressed on a median of three prior chemotherapy regimens were treated with chronomodulated HAIC with a combination of 5-FU, irinotecan and oxaliplatin with intravenous cetuximab, demonstrating an objective RR of $32 \%$ and a median OS of 13.7 months.

In short, there is compelling evidence from numerous studies that HAIC in combination with systemic chemotherapy is effective at achieving high local tumor RR with encouraging tumor downstaging potential and seems to be of benefit when applied earlier on in the course of disease. Large phase III trials are however currently lacking in this field and are required to validate these results, especially comparing HAIC with systemic chemotherapy vs. systemic chemotherapy alone. Further research is also ongoing into the prognostic effects of molecular markers (e.g., RAS and BRAF) on the outcome of HAIC as well as the addition of different targeted biological agents to HAIC regimens.

\subsection{Evidence for HAIC in the Adjuvant Setting}

In the adjuvant setting, early studies on the efficacy of HAIC yielded mixed results. A meta-analysis in 2006 [36] of 7 RCTs included 592 patients examining the efficacy of adjuvant HAIC conferred no significant advantage in OS between the pooled groups. 
However, in most of the studies, less than half of the patients were able to receive the complete planned HAIC protocol and trials also differed in the type of HAIC drug administered as well as the use of concurrent systemic chemotherapy. Despite this, the intrahepatic recurrence rates were doubled in the control group vs. the group receiving HAIC. In a 21-year analysis (1992-2012) of 2368 consecutive patients who had perioperative HAIC after curative-intent CRLM resection [37], median OS for patients with HAIC was 67 months vs. 44 months for those without. Overall, 5-year and 10-year OS for patients receiving HAIC compared to those without were $53 \%$ and $38 \%(p<0.001)$ vs. $38 \%$ and $24 \%(p<0.01)$, respectively. Despite this study spanning across the era prior to modern systemic chemotherapy, greater OS was still seen in the HAIC arm after propensity score matching. In a retrospective review of 98 patients [38] who had adjuvant oxaliplatin HAIC combined with systemic 5-FU vs. patients who received modern systemic chemotherapy alone, 3-year disease-free survival (DFS) was significantly longer in patients in the HAIC group compared to the systemic chemotherapy group $(33 \%$ vs. $5 \%, p<0.0001)$. Multivariate analysis confirmed that adjuvant HAI chemotherapy as well as R0 resection margin status were the only independent predictive factors for prolonged DFS. Whilst there was a trend for improved 3-year OS in the patients who received HAIC (75\% vs. $62 \%$, $p=0.17)$, this result was not statistically significant, possibly due to the patients in the HAIC group only receiving concurrent monotherapy. Currently, there are two RCTs underway to further evaluate the role of HAIC with systemic chemotherapy in the adjuvant setting. Postoperative Hepatic Arterial Chemotherapy in High-risk Patients as Adjuvant Treatment After Resection of Colorectal Liver Metastases (PACHA-01) is an ongoing phase II/III [39] trial in Europe with an estimated completion date in 2028, comparing adjuvant oxaliplatin HAIC with systemic 5-FU vs. systemic FOLFOX in patients with a high risk of CRLM recurrence (defined as having at least 4 prior resected CRLM). The primary endpoint is 18-month hepatic recurrence-free survival (RFS) rate with secondary objectives assessing feasibility, toxicity and efficacy. If hepatic recurrence RFS is successful in phase II, then the study will pursue to phase III, for which the primary endpoint will be 3-year RFS rate. The second study is the Adjuvant hepatic arterial infusion pump chemotherapy after resection of colorectal liver metastases in patients with a low clinical risk score (PUMP) trial [40], an open-label, phase III multi-center RCT in the Netherlands, evaluating the efficacy of adjuvant HAIC with systemic 5-FU compared to no systemic adjuvant therapy (standard of care in the Netherlands) in low-risk patients with resectable CRLM. The primary endpoint is PFS with secondary objectives of OS, hepatic PFS, safety and quality of life (QoL).

\subsection{Complications and Toxicity Related to HAIC}

Complications of HAIC can be divided into catheter-related complications and toxicity related to chemotherapy administration. Catheter-related complications include catheter migration, occlusion, hepatic arterial occlusion, extrahepatic perfusion or catheter/portrelated infection, which is consistently reported in approximately $10-20 \%$ of patients in the literature. In a review of 544 consecutive patients from 1986 to 2001 with surgically implanted pumps [41], there was an overall catheter/pump-related complication rate of $22 \%$. Notably, as the study period was over 25 years, complication rates significantly improved over the latter half of the study (1994-2001), probably due to increased operator experience as well as improved technique. As percutaneous techniques evolved, some authors sought to investigate whether catheter-related complications occurred less via a percutaneous implantation technique. Addressing this issue, a retrospective study of 126 patients was conducted in 2011 [42] comparing the complications related to percutaneous and surgically implanted catheters. While the investigators found that patients with percutaneous implanted catheters required an overall shorter hospital stay (1.8 days \pm 0.7 vs. 8.2 days \pm 22 ) and lower analgesic requirement ( 2.0 doses \pm 0.9 vs. 9.7 doses \pm 3.2 ), there was no significant difference in the number of catheter-related complications per chemotherapy course (percutaneous $9 \%$ vs. surgical $8 \%, p=0.9$ ) or rates of HAIC discontinuation (percutaneous $12 \%$ vs. surgical $19 \%, p=0.12$ ). In a more recent phase II multi-center study conducted in 
Japan [43], the efficacy and adverse events of HAIC using percutaneous catheter placement were evaluated. There was an overall catheter-related complication rate of $19 \%$, of which HAIC treatment was discontinued due to catheter/procedural-related complications in $15.6 \%$ of patients (12/77 patients) — this was similar to the reported rates of surgically implanted catheters in previous studies. In a comprehensive review of 4580 cases in 2001 [44], the most common drug toxicities related to HAIC were gastrointestinal symptoms (22\%), chemical hepatitis $(19 \%)$ and bone marrow toxicity $(8 \%)$. Hepatobiliary toxicity evident by serum transaminitis, hyperbilirubinemia and biliary sclerosis were also serious issues, with a higher incidence in FUDR [45,46]. To mitigate this risk, intra-arterial dexamethasone was administered together with FUDR. In a randomized study of 50 patients, those receiving dexamethasone plus FUDR had a trend towards decreased hyperbilirubinemia $(p=0.07)$ with increased response rate $(p=0.03)$ [47]. Alternatively, as biliary sclerosis is not seen with 5-FU HAIC, some investigators have toggled between regimens of FUDR HAIC and 5-FU HAIC to reduce hepatotoxic effects that may lead to early treatment termination $[46,48]$.

\section{Trans-Arterial Chemoembolization (TACE)}

TACE is a trans-arterial, catheter-based locoregional treatment to the liver, combining injection of chemotherapy drug and embolic material directly into the hepatic artery. The rationale of TACE is two-fold; firstly, to deliver a high dose of chemotherapeutic drug directly to tumor tissue, thereby reducing systemic toxicity, and secondly to interrupt blood supply, causing ischemia and necrosis. These mechanisms are supposedly synergistic in nature, allowing delayed washout of the anti-tumoral agent and enabling a prolonged duration of action. TACE has long been established as a first-line treatment for Barcelona Clinic Liver Cancer (BCLC) intermediate stage hepatocellular carcinoma (HCC) [49], although in the setting of $C R C$, the primary indication for TACE is as second-line treatment in patients with chemo-refractory CRLM with liver-only metastatic disease.

In TACE, the technique and type of chemotherapeutic/embolic agent injected varies across different centers. Regardless, the principle remains the same: vascular access is first obtained either from the common femoral or radial artery. A catheter is passed through the celiac trunk into the main hepatic artery where standard, high-quality angiography is performed, prior to delivery of the chemo-embolic drugs. The angiogram serves several purposes: to delineate the hepatic arterial anatomy and potential variations, determination of tumor arterial feeders, identification of arteries to be avoided during treatment delivery (e.g., right gastric, gastroduodenal artery, to prevent inadvertent non-target embolization) and evaluation of portal vein patency [50]. Modern techniques include the use of conebeam computed tomography (CBCT) to significantly increase detection of tumors as well as tumor feeding arteries during TACE [51]. After the chemo-embolic drugs are delivered, this is usually followed with an embolizing agent (e.g., Gelfoam, polyvinyl alcohol (PVA) or calibrated microspheres). The optimal endpoint of TACE has not been formally established, but generally, most interventionalists would embolize until stasis, or near stasis, achieving a 'tree-in-winter' appearance [52]. Multiple treatment sessions are often required, alternating in a lobar fashion, especially in the setting of bilobar disease to ensure satisfactory treatment, as well as to prevent drug toxicity and avoid potential hepatic decompensation related to the embolization.

The use of conventional TACE (CTACE) for unresectable CRLM, which is chemotherapeutic drugs mixed with Lipiodol (Guerbet, Paris, France) to form a liquid emulsion, was largely adopted from its use in HCC. Common drugs used in CTACE include Mitomycin, Cisplatin and Doxorubicin. With the advent of drug-eluting bead (DEB, DC/LC Bead, BTG, UK Ltd.) technology, the use of cTACE alone in the setting of CRLM dwindled, probably related to limited efficacy for increasing OS and the lack of prospective trials. DEB-TACE utilizes calibrated microspheres loaded with cytotoxics (e.g., irinotecan) to allow a more prolonged and reproducible manner of drug release [53]. The use of DEB also results in a lower peak plasma concentration of chemotherapeutic drugs compared to CTACE, essentially reducing systemic side effects and local toxic effect to healthy liver parenchyma [54]. 
In the context of CRLM, the results obtained with DEB loaded with irinotecan (DEBIRI) have been promising and will be discussed specifically in a later section. To date, there is no head to head comparison of DEBIRI-TACE to CTACE, thus, the decision to offer one over the other is often a matter of institutional preference [55].

\subsection{Evidence for Bland Embolization (TAE)}

The use of trans-arterial bland embolization (TAE) for unresectable CRLM has been investigated, although data on the subject is limited and to our knowledge is not widely used. A prospective study in 1990 evaluating 61 patients with unresectable CRLM, randomized to either bland-TAE (using gelatin sponge and autologous lyophilized dura matter), HAIC or no treatment showed no significant survival benefit in the TAE arm [56]. In a separate study evaluating the advantages of DEBIRI in a rat colorectal liver metastases model [57], embolization with DEB alone showed no effect on tumor burden, compared with a dose-dependent response with DEBIRI. Findings from this study suggest that both the effects of drug and embolization are important to achieve a tumoricidal response. In contrast, a pilot study by Tanaka et al. evaluated the response of repeated bland-TAE with 100 um calibrated microspheres administered through an implantable port-catheter system, in two heavily pre-treated patients with unresectable CRLM [58]. The procedure was repeated four times in intervals of 14-21 days due to the initial observation of hepatic arterial recanalization and recurrent tumor staining 13 days after the first TAE procedure. Two-month computed tomography (CT) follow-up after the procedures for both patients showed tumor necrosis and an OS approaching 6 months without any additional therapy. There may be an ongoing role for bland-TAE in combination with percutaneous ablation for oligometastatic, unresectable CRLM, where several studies have shown the synergistic effects of combining both modalities to achieve larger ablation volumes and reducing peripheral recurrence [59].

\subsection{Evidence for $C T A C E$}

In the largest series to date evaluating the long-term results of cTACE in 564 patients with unresectable, chemo-refractory CRLM, overall RR was 65\% with reported 1-, 2- and 3 -year survival rates of $62 \%, 28 \%$ and $7 \%$, respectively (median OS of 14 months) [60]. TACE was used during second-line treatment or later, and patients were treated for an average of 6 sessions (range: 3-29). Chemotherapy drug protocols included Mitomycin $\mathrm{C}$, Mitomycin C/Irinotecan, Mitomycin C/Gemcitabine or a combination of Mitomycin $\mathrm{C} /$ Irinotecan/Cisplatin with embolization performed using Lipiodol and starch microspheres. There is currently no formal study evaluating the use of cTACE in the first-line setting. However, a study by Albert et al. [61], evaluating 121 patients with cTACE, included 63 patients (52\%) who had undergone $0-1$ line of prior systemic treatment using Cisplatin, Doxorubicin and Mitomycin C mixed with Lipiodol and PVA particles. Not surprisingly, patients who had $0-1$ lines of prior systemic treatment fared better than those who had 3-5 lines of prior treatment, with a median OS of 12 months and 6 months respectively, with an overall RR of $43 \%$ and a median OS of 9 months after the start of treatment for all patients. Results from another study evaluating 66 patients ( $46 \%$ chemo-naïve) treated with 5-FU/GM-CSF/Melphalan with Lipiodol and Gelfoam reported an overall RR of $88 \%$ (WHO criteria) [62]. Median survival for this study, however, was not reached, as only $66 \%$ of patients survived at 2 years. Overall, the available data on CTACE shows limited efficacy at increasing OS, especially in the era of modern systemic chemotherapy. Together with the lack of prospective trials, the use of DEBIRI-TACE seems to have superseded CTACE alone in the setting of unresectable CRLM. There does however appear to be a role for CTACE in conjunction with other therapies, such as percutaneous ablation for the treatment of oligometastatic, unresectable CRLM. In a retrospective review of 452 patients undergoing repetitive $\mathrm{CTACE}$, two-hundred and nineteen patients were treated in a neoadjuvant setting followed by percutaneous thermal ablation [63]. This group of patients fared better in terms of median PFS and OS compared to those treated with CTACE only in a palliative 
setting (11 months and 26 months vs. 6 months and 13 months, respectively). In a separate phase II study examining 25 patients treated with TACE (degradable starch microsphere and Mitomycin C) followed by radiofrequency ablation (RFA), 2-year local tumor control rate was $92 \%$, with a median OS of 48.4 months [64].

\subsection{Evidence for DEBIRI-TACE}

The data on the efficacy of DEBIRI TACE is more established based on a series of limited Phase II trials [65-68], as well as a randomized phase III trial [69], summarized in Table 2. In a multicenter, single-arm prospective study of 55 patients treated with multiple prior lines of chemotherapy who underwent a total of 99 DEBIRI treatments (median of 2 sessions, range: 1-5), overall RR was 75\% at 1 year, with PFS and OS of 11 months and 19 months, respectively [65]. In a separate study, Aliberti et al. evaluated 82 heavily pre-treated patients (failed at least 2 lines of prior systemic chemotherapy) treated with DEBIRI. Median follow-up time was 29 months with reported RR of $78 \%$ at 3 months, PFS and OS of 8 months and 25 months, respectively [66]. In a more recent prospective phase II study also evaluating heavily pre-treated patients, Izzei et al. [67] evaluated 20 patients who had progressed on at least 2 prior standard lines of chemotherapy with an additional $50 \%$ of patients having failed 3 or more lines. An objective RR of $60 \%$ (according to modified RECIST 1.1 (mRECIST)) was reported with a median PFS and OS of 4 months and 7.3 months, respectively. The less favorable outcome achieved in this study could have been related to several factors, such as the small sample size as well as $40 \%$ (8 out of 20 patients) of patients discontinuing treatment before completion. The efficacy of DEBIRI in addition to a biological agent alone, such as bevacizumab, has also been examined. In a prospective study of 30 pre-treated patients [68], randomized to either DEBIRI alone or DEBIRI with bevacizumab, the addition of bevacizumab showed an increase in RR (77\% vs. $19 \%, p<0.01)$, PFS ( 6 months vs. 4 months, $p<0.01)$ and median OS (12 months vs. 5.8 months, $p<0.01$ ) when compared to the DEBIRI alone arm. In the only small phase III RCT conducted by Fiorentini et al. [69], seventy-four patients with liver-only metastatic CRLM were randomized to receiving DEBIRI or FOLFIRI. All patients enrolled had undergone at least 2 lines of prior systemic chemotherapy. Patients undergoing DEBIRI had two treatment sessions for each involved lobe, one month apart. Whilst some have questioned the statistical rigor of this study, there was an overall increase in OS of 7 months in patients treated with DEBIRI vs. FOLFIRI (22 months vs. 15 months respectively, $p=0.031$ ), as well as improved PFS in the DEBIRI arm (7 vs. 4 months, $p=0.006)$. On examining QoL, patients treated with DEBIRI also enjoyed longer duration QoL with less significant side effects ( 8 vs. 3 months, $p<0.001)$. 
Table 2. Selected prospective trials for DEBIRI TACE.

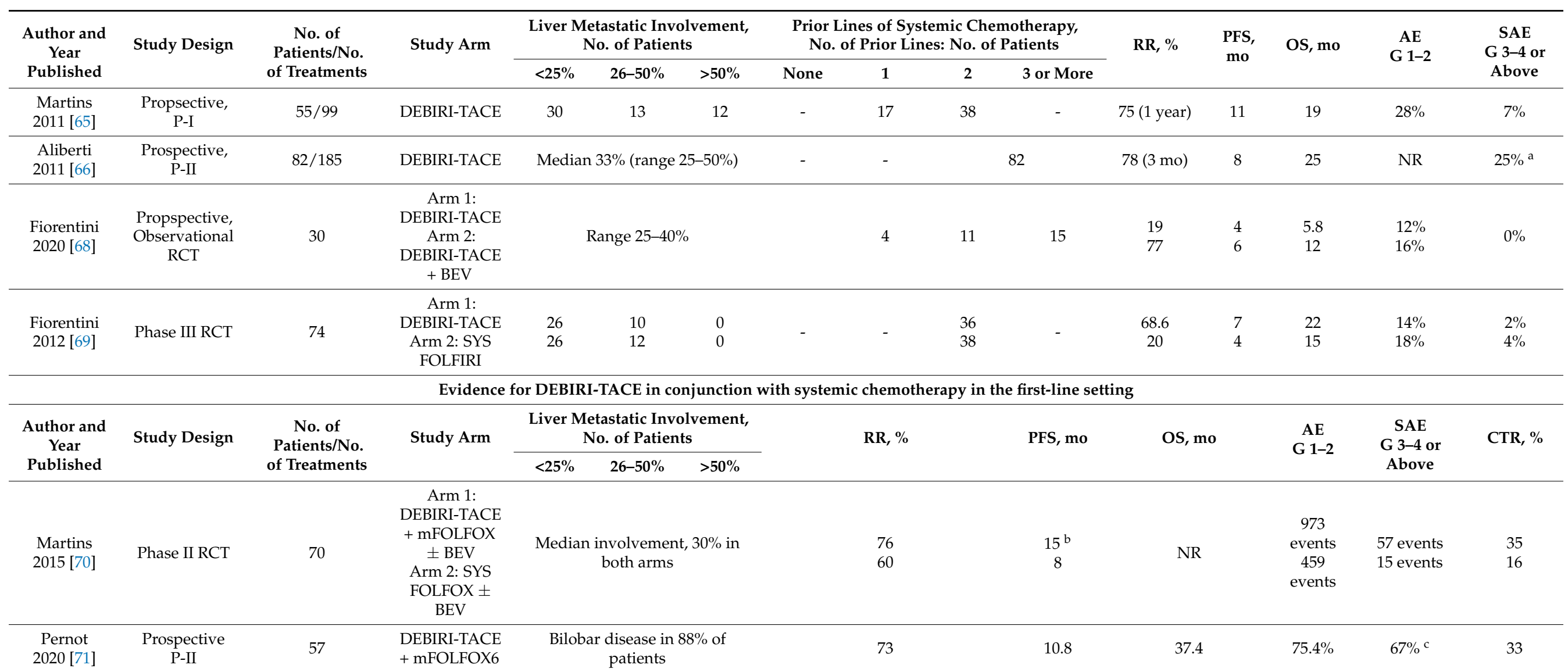

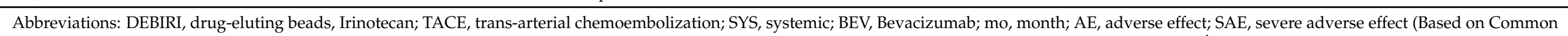

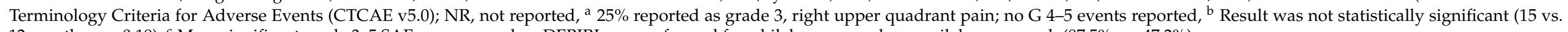
12 months, $p=0.18),{ }^{c}$ More significant grade 3-5 SAE were seen when DEBIRI was performed for a bilobar approach vs. unilobar approach (87.5\% vs. $\left.47.2 \%\right)$. 
In the first-line setting, Martins et al. evaluated 10 chemo-naïve patients in a phase I study treated with DEBIRI and systemic mFOLFOX \pm bevacizumab [72]. Despite a small sample size, the results were impressive with a 12-month RR of $100 \%$ and median OS of 15 months: four patients (40\%) were down-staged successfully to undergo secondary hepatic CRLM resection with an overall pathological response rate of 90-95\% [73]. This high degree of pathological necrosis was mirrored in the Chemoembolization Using Irinotecan Bead Prior to Surgery in Metastatic Colorectal Cancer (PARAGON-II) study [74], where 40 patients with easily resectable CRLM were treated with a single session of DEBIRI, 1 month prior to surgery in a neoadjuvant setting. Seventy-six percent of targeted, resected lesions showed a histologically major or complete pathological response. In a randomized phase II trial of 70 patients evaluating DEBIRI in combination with systemic mFOLFOX \pm bevacizumab as compared to FOLFOX \pm bevacizumab alone in chemo-naïve patients, there was an overall improvement in 6-month RR in the DEBIRI arm (76\% vs. 60\%, $p=0.05)$, which led to a significantly higher CTR rate (35\% vs. $16 \%, p=0.05)$ and longer median PFS (15 vs. 8 months, $p=0.18$ ), albeit non-significant [70]. No significant difference in chemotherapy-associated adverse events were reported between the study arms. A more recent phase II study [71] evaluated 57 chemo-naïve patients with liver-dominant CRLM who received both DEBIRI and mFOLFOX6. The majority of patients received 4 DEBIRI sessions, in an alternating fashion between the right and left lobe, although $37 \%$ patients had bilobar treatment in 2 sessions which subsequently resulted in more serious toxicities encountered in this subgroup. Despite the study not meeting its endpoint of $>75 \%$ PFS at 9 months (actual 9-month PFS of 54\%), objective RR of 73\% and median PFS and OS of 10.8 months and 37.4 months respectively, were demonstrated. Notably, nineteen patients $(33 \%)$ were suitably down-staged to undergo a secondary R0 resection with or without ablative therapy.

\subsection{Complications of TACE}

Approximately $30 \%$ of patients undergoing DEBIRI-TACE develop mild adverse complications, with the most common being abdominal pain, hypertension, nausea and vomiting [75]. Post-embolization syndrome can occur in up to two thirds of patients, characterized by abdominal pain, nausea, fatigue, transient derangement in liver function and fever without sepsis in the peri- or post-treatment period [76]. Severe complications such as hepatic abscess, hepatic failure, pancreatitis and peptic ulceration are rare with gastrointestinal ischemia related to non-target embolization, occurring in $<1 \%$ of patients [23]. Bile duct injury has been reported in up to $11 \%$ of patients undergoing TACE, due to the bile ducts being solely perfused by the hepatic arterial vasculature [77]. Due to the local delivery of chemotherapy, systemic drug toxicity is rare. An increase in adverse complications and prolonged hospital stay have been associated with the lack of hepatic arterial lidocaine use, three or more treatments, obtaining complete stasis during TACE, dose of $>100 \mathrm{mg}$ of DEBIRI per treatment session, serum bilirubin $>2.0 \mathrm{mg} / \mathrm{dL}$ and $>50 \%$ tumor involvement of the liver [78]. When comparing DEB-TACE to cTACE, both have a similar toxicity profile, although DEB-TACE has demonstrated fewer drug-related adverse events when compared to cTACE [79].

\section{Y-90 Selective Internal Radiation Therapy (SIRT)}

The role for external beam radiation therapy in the treatment of primary and secondary liver tumors has historically been limited by the low-radiation threshold of normal, healthy liver parenchyma [80]. Given this limitation, and the need for significantly higher radiation doses to achieve a tumoricidal effect, SIRT has emerged over the past few decades as a treatment option for patients with unresectable liver tumors. Micron-sized spheres (20-60 $\mu \mathrm{m})$ loaded with a radioisotope are introduced using percutaneous trans-arterial techniques directly into the hepatic arterial vasculature supplying tumor tissue [81]. Yytrium-90 (Y-90), a pure beta-emitter, is the most commonly used radionuclide to label microspheres due to its favorable characteristics: mean tissue penetration of $2.5 \mathrm{~mm}$ (maximum $11 \mathrm{~mm}$ ) and 
relatively short half-life of $64.2 \mathrm{~h}$, thus allowing delivery of high-radiation doses (as high as $150 \mathrm{~Gy}$ ) to tumor tissue, whilst limiting the radiation effects to the background liver parenchyma [82]. There are currently two commercially available microspheres composed of either glass (Therapshere ${ }^{\circledR}$; BTG International, London, UK) or resin (SIR-Spheres ${ }^{\circledR}$; Sirtex Medical, North Sydney, Australia). SIR-Spheres gained full premarketing approval by the Food and Drug Administration (FDA) in 2002, for the treatment of unresectable CRLM in conjunction with intrahepatic FUDR. This was largely based on the results of a randomized phase III trial in which 74 patients with liver only, unresectable CRLM were assigned to receiving either HAI-FUDR alone or HAI-FUDR with a single SIRT administration [15]. Patients in the combination SIRT arm demonstrated significantly longer median time to progression (TTP) (15.9 months vs. 9.7 months in the HAI-FUDR alone arm) as well as demonstrated higher OS rate at 1,2 and 3 years $(72 \%, 39 \%$ and $17 \%$ vs. $68 \%, 29 \%$ and $6.5 \%)$, albeit not statistically significant. In contrast, Therapsheres gained approval by the FDA in 1999 under a humanitarian device exemption for the treatment of unresectable HCC in patients with appropriately positioned hepatic arterial catheters [81]. In a practical sense, there are physical differences between the two types of spheres, mainly size, and potential activity per sphere which affects the embolic potential as well as dosimetry for treatment planning. In the setting of CRC, Y-90 SIRT has primarily been used in patients with liveronly or liver-dominant unresectable CRLM, with chemo-refractory disease. However, in recent years, its role as first-line treatment in combination with systemic chemotherapy, as well as in a neoadjuvant setting in patients with initially unresectable CRLM, have also been examined.

Technically, Y-90 SIRT treatment is divided into two parts: mapping and treatment. This is usually performed up to 2 weeks apart through two outpatient visits, or in some centers, all performed on the same day [83]. For the mapping stage, once vascular access is obtained, a hepatic angiogram is performed to assess the hepatic vasculature and identify the vessels supplying the tumors. In some cases, this may also include identification of any parasitized tumor-supplying vessels, arising from extra-hepatic arteries. In this context, these are usually coil-embolized during this stage, to consolidate tumoral blood supply via the main intrahepatic arteries [84]. It is also of critical importance to identify arteries supplying extrahepatic structures such as the stomach, duodenum and pancreas to avoid non-target deposition of $\mathrm{Y}-90$ radioactive microspheres during the subsequent treatment session, which could result in serious complications such as non-healing ulcers and pancreatitis [85] - these vessels are either avoided, or prophylactically embolized at this stage. Once the desired microcatheter position(s) is chosen, technetium- $99\left({ }^{99} \mathrm{mTc}\right)$-labelled macroaggregated albumin (MAA) is injected as a surrogate, into each artery planned for Y-90 microspheres delivery. The purpose of this is two-fold, first, to calculate lung shunt fraction (LSF) using planar scintigraphy, and second, to perform a single photon emission CT (SPECT) image to evaluate for inadvertent gastrointestinal deposition as well as to predict intrahepatic tumoral microsphere distribution [55]. Patients with LSF of more than $20 \%$, corresponding to greater than $30 \mathrm{~Gy}$ of radiation delivered to the lungs, cannot undergo SIRT due to the potential risk of irreversible radiation-induced pneumonitis. During the treatment session, the Y-90 microspheres are administered at the planned microcatheter position(s), and thereafter, a bremsstrahlung single photon emission computed tomography (SPECT) study is performed to confirm satisfactory tumor coverage [86]. In the majority of patients who have bilobar disease, whole liver treatment can be performed in a single session, or in two sequential lobar treatments $4-8$ weeks apart if the patient's liver reserve is in question. In practice, single-session treatments are preferred for logistical reasons, as well as to prevent the risk of non-target Y-90 microsphere deposition due to potential interval change in the hepatic arterial vasculature between treatment sessions. 


\subsection{Evidence for Y-90 SIRT in Chemo-Refractory Patients}

The relevant data on Y-90 SIRT is illustrated in Table 3, with the majority of data pertaining to patients who have chemo-refractory disease. Y-90 SIRT has shown the most benefit in this subset of patients, demonstrating objective RR of $10-48 \%$, based on RECIST criteria, and an OS ranging from 9.6 to 14.9 months [16,87-95]. This is encouraging, as the median OS in chemo-refractory patients is approximately $4-6$ months with current systemic treatment options such as TAS-102 [96] and Regorafenib [97], which have shown a modest but significant OS benefit in phase III trials of approximately 2 months when compared to best supportive care. In a phase I dose-escalation study of 25 patients' refractory to systemic first-line 5-FU, treated with second-line irinotecan and Y-90 SIRT, RR was $48 \%$ with a median PFS and OS of 6 months and 12.2 months, respectively [87]. In a large, single-center, retrospective study by Saxena et al. [88], three-hundred and two patients underwent resin Y-90 SIRT for unresectable, chemo-refractory CRLM. One-hundred and forty-two patients $(47 \%)$ included had two or more lines of prior chemotherapy regimens. Most patients presented with bilobar CRLM $(n=261,86 \%)$, with 26 patients $(9 \%)$ having $>51 \%$ replacement of the liver by tumor. Over a median follow-up period of 7.2 months (range: 0.2-72.8 months), median OS was 10.5 months with a 24 -month survival of $21 \%$. On multivariate analysis, factors associated with a poorer prognosis were poor radiological response to treatment (determined on RECIST criteria), extensive replacement of hepatic parenchyma by tumor, number of previous lines of chemotherapy and low pre-procedure hemoglobin. A multicenter study by Kennedy et al. [89] evaluated 208 patients who underwent Y-90 SIRT with SIR-Spheres in patients with unresectable CRLM in a salvage setting - patients included had failed up to 3 standard lines of chemotherapy. Patients either had CT or positron emission tomography (PET) imaging follow-up within 3 months and showed a RR of $36 \%$ on CT (CR defined as disappearance of all lesions, PR defined as 50\% decrease in tumor number or size by 1 measurement or necrosis of most lesions determined by Hounsfield values in the center of a lesion) and 91\% RR on PET. This dramatic distinction is due to the poor sensitivity of RECIST criteria in detecting response to Y-90 SIRT, as evaluation is based on tumor size and morphology alone [98]. PET-CT has the benefit of being able to assess tumor metabolic activity, regardless of tumor size, hence increasing sensitivity to detect treatment response and has also been mentioned as a mode of imaging follow-up for Y-90 SIRT patients in the latest NCCN guidelines [13]. Overall, median survival was significantly longer in patients that responded to Y-90 SIRT, compared to non-responders (10.4 months vs. 4.5 months, $p=0.0001$ ). In a multi-center study by Cosimelli et al. [90] of 50 heavily pre-treated patients who failed at least 3 lines of systemic chemotherapy (FOLFOX and FOLFIRI regimens) treated with Y-90 SIRT (majority treated with a single treatment), RR was $24 \%$ with a median PFS and OS of 3.7 months and 12.6 months, respectively. Patients who responded to SIRT on imaging also demonstrated improved OS compared to non-responders ( 16 months vs. 8 months, $p<0.0006)$. Other studies have also shown the safety and efficacy of Y-90 SIRT in heavily pre-treated patients besides prior systemic chemotherapy. A phase I study by Sofocleous et al. [91] evaluated 19 patients undergoing Y-90 SIRT with progression after FUDR-HAIC and systemic chemotherapy. All patients had progressed after at least 2 or more prior lines of systemic chemotherapy and more than 1 prior line of HAIC with the mean time from primary diagnosis to Y-90 SIRT being 53.8 months. Median follow-up time was 31.2 months after Y-90 SIRT, with reported median PFS and OS of 2 months and 14.9 months, respectively. Post Y-90 SIRT treatment, seventeen patients $(89.5 \%)$ went on to receive further systemic chemotherapy and 9 patients $(53 \%)$ went on to receive further HAIC for liver disease progression. Despite this, Y-90 SIRT did not appear to adversely impact the tolerability of future subsequent treatments. Furthermore, in more than half of the patients that received HAIC after Y-90 SIRT in this cohort, there were no cases of radiation-induced liver disease (RILD) or other significant toxicities. In a separate single-center retrospective study, Sofocleous et al. [92] evaluated the outcomes of resin Y-90 SIRT in 53 heavily pre-treated patients. In this study, besides $28 \%$ of patients having had 3 or more lines of prior systemic chemotherapy, twenty-nine patients 
(55\%) had previous HAIC, and 26 patients (49\%) had prior liver surgery. Within a median follow-up period of 15 months, median liver PFS and OS were 4.7 months and 12.7 months, respectively. Post-Y-90 SIRT, 34 patients (64\%) went on to receive further additional therapy for disease progression, such as systemic chemotherapy, HAIC or thermal ablation, without any significant increase in complications or clinical toxicities. Together, these studies support the fact that Y-90 SIRT does not preclude patients from undergoing future subsequent liver-directed therapies in the event of liver disease progression. The largest series available to date evaluating the use of SIR-Spheres, the Metastatic colorectal cancer liver metastasis Outcomes after Radioembolization (MORE) study included 606 patients demonstrating a median OS of 9.6 months [93]. Y-90 SIRT was used as second-line treatment in 35.3\% of patients, third-line treatment in $31.6 \%$ of patients and fourth-line treatment in $27.1 \%$ of patients. Not surprisingly, patients treated with Y-90 SIRT as second-line treatment fared better than those as fourth-line treatment (median OS of 13 months vs. 8.1 months, $p<0.001$ ), which was shown to be an independent predictor of improved survival. Other significant independent predictors that worsened survival were the presence of extrahepatic disease, extent of tumor burden and baseline liver function. In the only phase III RCT of 46 patients (refractory to oxaliplatin and irinotecan) by Hendlisz et al. [16], comparing Y-90 SIRT with 5-FU systemic chemotherapy compared to 5-FU chemotherapy alone [16], there was improved median PFS in the Y-90 SIRT arm compared to the chemotherapy arm (4.5 months vs. 2.1 months, $p=0.03$ ), although this did not confer to a significant OS benefit (10 months vs. 7.3 months, $p=0.8$ ). This may have been due to the small sample size and the lack of power to detect a significant difference [99]. Additionally, cross-over was also allowed for this study, with 10 patients (43\%) in the 5-FU chemotherapy-only arm receiving further Y-90 SIRT monotherapy, which may have also confounded the OS data.

Pertaining to glass microspheres, similar results have been procured, but to a lesser degree, partly due to the different approved indications by the FDA. A study by Lewandowski et al. [94] evaluated 214 patients treated by Y-90 SIRT over a 12-year period spanning the era before the addition of biological agents: a median OS of 10.6 months was reported from the first Y-90 SIRT treatment, which was promising, considering $42 \%$ of patients had extrahepatic disease. Independent predictors of survival were similar to those seen in other large studies such as $<2$ prior chemotherapy lines, no prior biological agents and those who received Y-90 SIRT in the earlier stages of disease. The largest multi-center retrospective review to date evaluating the safety and efficacy of Theraspheres by Hickey et al. [95] included 531 patients and reported a similar median OS of 10.6 months from first Y-90 SIRT treatment-more than half of patients had received 3 prior systemic agents prior to Y-90 SIRT treatment (56\%). Currently, a multi-center phase III RCT is underway (Efficacy Evaluation of TheraSphere Following Failed First Line Chemotherapy in Metastatic Colorectal Cancer, EPOCH trial) evaluating the efficacy of Therapshere-based Y-90 SIRT in conjunction with second-line chemotherapy vs. chemotherapy alone in patients with CRLM who have failed first-line systemic chemotherapy [102]. 
Table 3. Selected prospective trials and retrospective studies for Y-90 SIRT.

\begin{tabular}{|c|c|c|c|c|c|c|c|c|c|c|c|c|c|c|c|c|c|c|}
\hline \multirow{2}{*}{$\begin{array}{l}\text { Author and } \\
\text { Year } \\
\text { Published }\end{array}$} & \multirow{2}{*}{$\begin{array}{c}\text { Study } \\
\text { Design }\end{array}$} & \multirow{2}{*}{$\begin{array}{l}\text { No. of } \\
\text { Patients }\end{array}$} & \multirow[t]{2}{*}{ Study Arm } & \multicolumn{3}{|c|}{$\begin{array}{l}\text { Liver Metastatic } \\
\text { Involvement, } \\
\text { No. of Patients }\end{array}$} & \multicolumn{4}{|c|}{$\begin{array}{l}\text { Prior Lines of Systemic } \\
\text { Chemotherapy/Patients }\end{array}$} & \multirow{2}{*}{$\begin{array}{l}\text { Mean } \\
\text { Activity } \\
\text { (Gbq) }\end{array}$} & \multirow[t]{2}{*}{ RR, \% } & \multirow[t]{2}{*}{$\begin{array}{l}\text { PFS, } \\
\text { mo }\end{array}$} & \multirow[t]{2}{*}{$\begin{array}{c}\text { Liver } \\
\text { PFS, mo }\end{array}$} & \multirow{2}{*}{\multicolumn{2}{|c|}{ OS, mo }} & \multirow[t]{2}{*}{$\begin{array}{c}\mathrm{AE} \\
\mathrm{G} \mathrm{1-2}\end{array}$} & \multirow{2}{*}{$\begin{array}{l}\text { SAE } \\
\text { G 3-4 } \\
\text { Above }\end{array}$} \\
\hline & & & & $<25 \%$ & $26-50 \%$ & $>50 \%$ & None & 1 & 2 & 3 or More & & & & & & & & \\
\hline $\begin{array}{c}\text { Gray } 2001 \\
\text { [15] }\end{array}$ & $\begin{array}{c}\text { Phase III } \\
\text { RCT }\end{array}$ & 74 & $\begin{array}{l}\text { Arm 1: Y-90 SIRT } \\
\text { (Resin) + HAI FUDR } \\
\text { Arm 2: HAI FUDR }\end{array}$ & NR & NR & NR & - & \multicolumn{3}{|c|}{$\begin{array}{l}5 \\
5\end{array}$} & 2.2 & $\begin{array}{l}37 \\
14\end{array}$ & NR & $\begin{array}{l}15.9 \\
9.7\end{array}$ & \multicolumn{2}{|r|}{$\begin{array}{c}17 \\
15.9\end{array}$} & NR & $\begin{array}{l}64 \% \\
66 \%\end{array}$ \\
\hline $\begin{array}{l}\text { Kennedy } \\
2005[89]\end{array}$ & $\begin{array}{c}\text { Prospective, } \\
\text { P I-II }\end{array}$ & 208 & Y-90 SIRT (Resin) & NR & NR & NR & - & - & 198 & 10 & 1.75 & 36 & NR & NR & \multicolumn{2}{|r|}{$\begin{array}{c}10.5(\mathrm{R}) \\
4.5 \text { (NOR) }\end{array}$} & $24.5 \%$ & $28.5 \%$ \\
\hline $\begin{array}{l}\text { Cosimelli } \\
2010[90]\end{array}$ & Prospective & 50 & Y-90 SIRT (Resin) & 20 & 30 & 0 & - & - & - & 50 & 1.7 & 24 & 3.7 & NR & \multicolumn{2}{|r|}{12.6} & $42 \%$ & $4 \%^{a}$ \\
\hline $\begin{array}{l}\text { Kennedy } \\
2015[93] \\
\end{array}$ & Retrospective & 606 & Y-90 SIRT (Resin) & 388 & 148 & 22 & 35 & 206 & 184 & $158^{\mathrm{b}}$ & 1.46 & NR & NR & NR & \multicolumn{2}{|r|}{9.6} & $41.4 \%^{c}$ & $10.2 \%^{\mathrm{d}}$ \\
\hline $\begin{array}{l}\text { Hendlisz } \\
2010 \text { [16] }\end{array}$ & $\begin{array}{c}\text { Phase III } \\
\text { RCT }\end{array}$ & 44 & $\begin{array}{l}\text { Arm 1: Y-90 SIRT } \\
\text { (Resin) + SYS 5-FU } \\
\text { Arm 2: SYS 5-FU }\end{array}$ & NR & NR & NR & - & \multicolumn{3}{|c|}{$\begin{array}{l}20 \\
13\end{array}$} & 1.79 & $\begin{array}{c}10 \\
0\end{array}$ & $\begin{array}{l}4.5 \\
2.1\end{array}$ & $\begin{array}{l}5.5 \\
2.1\end{array}$ & \multicolumn{2}{|r|}{$\begin{array}{l}10.0 \\
7.3^{*}\end{array}$} & NR & $\begin{array}{l}5 \% \\
27 \%\end{array}$ \\
\hline $\begin{array}{l}\text { Lewandowski } \\
2014[94]\end{array}$ & Prospective & 214 & Y-90 SIRT (Glass) & 174 & 31 & 9 & - & 14 & 35 & 160 & 2.35 & NR & NR & NR & \multicolumn{2}{|r|}{10.6} & $50 \%$ & $39 \%$ e \\
\hline $\begin{array}{c}\text { Hickey } 2016 \\
{[95]}\end{array}$ & Retrospective & 531 & Y-90 SIRT (Glass) & 370 & 103 & 58 & 15 & \multicolumn{2}{|c|}{216} & 295 & NR & NR & NR & NR & & 10.6 & $55 \%$ & $13 \%$ \\
\hline & & & & Evi & nce for Y-9 & SIRT in & onjuncti & n with & stemic & emotherapy & the first-lin & tting & & & & & & \\
\hline & & & & $<25 \%$ & $26-50 \%$ & $>50 \%$ & & & & & & & & & & & & \\
\hline $\begin{array}{l}\text { van Hazel } \\
2004 \text { [100] }\end{array}$ & Phase II RCT & 21 & $\begin{array}{c}\text { Arm 1: Y-90 SIRT } \\
\text { (Resin) + SYS } \\
\text { 5-FU/ LV } \\
\text { Arm 2: SYS 5-FU/LV }\end{array}$ & $\begin{array}{l}8 \\
7\end{array}$ & $\begin{array}{l}3 \\
3\end{array}$ & & & 2.25 & & $\begin{array}{c}73 \\
0\end{array}$ & & & NR & & $\begin{array}{l}29.4 \\
12.8\end{array}$ & $\begin{array}{c}5 \\
\text { events }\end{array}$ & $13 \mathrm{e}$ & ents \\
\hline $\begin{array}{c}\text { Wasan } 2017 \\
{[101]}\end{array}$ & $\begin{array}{l}\text { Phase III } \\
\text { RCT }\end{array}$ & 1103 & $\begin{array}{c}\text { Arm 1: Y-90 SIRT } \\
\text { (Resin) + SYS } \\
\text { FOLFOX } \\
\text { Arm 2: SYS FOLFOX }\end{array}$ & $\begin{array}{l}374 \\
380\end{array}$ & $\begin{array}{l}37 \\
17\end{array}$ & & & $\mathrm{NR}^{\mathrm{f}}$ & & $\begin{array}{l}72 \\
63\end{array}$ & & & $\begin{array}{l}20.5 \\
12.6\end{array}$ & & $\begin{array}{c}23.4 \\
23.9^{*}\end{array}$ & $\begin{array}{l}26 \% \\
33 \%\end{array}$ & & \\
\hline
\end{tabular}

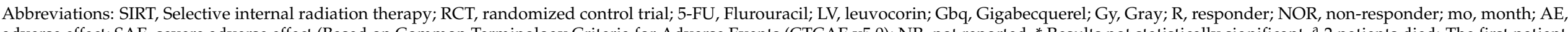

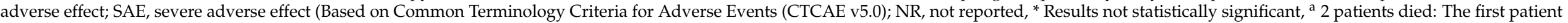

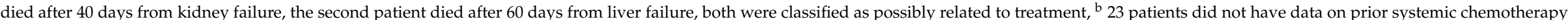

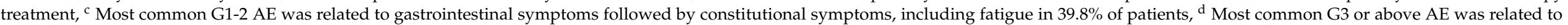

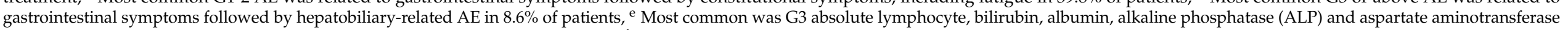
(AST) toxicities. Grade 4 absolute lymphocyte and ALP toxicities observed in 5\%., ${ }^{\mathrm{f}}$ Median $1.4 \mathrm{GBq}$ (range $0.4-3.1 \mathrm{Gbq}$ ) reported in the SIRFLOX study only. 
Several studies have specifically investigated different prognostic factors affecting the oncologic outcomes of Y-90 SIRT treatment to refine patient selection and balance the benefits of treatment response and life prolongation against the hazards of over-aggressive treatment in this cohort of chemo-refractory patients. In 2016, Damm et al. [103] analyzed 106 salvage patients (failed at least 1 line of prior systemic chemotherapy, with 28 patients, $26 \%$, failing 4 lines or more) who underwent Y-90 SIRT. A predictive scoring system was proposed, comprising of hepatic tumor load, carcinoembryonic antigen (CEA) and/or cancer antigen 19-9 (CA 19-9), and Karnofsky Index after these factors were found to have a significant impact on OS upon multivariate Cox regression analysis. In this study, median PFS and OS were 3.5 and 6.7 months respectively, after first Y-90 SIRT treatment. This survival rate was worse when compared to other Y-90 SIRT salvage series mentioned previously, which was attributed to a potentially over-aggressive indication for Y-90 SIRT treatment. However, when applying the predictive scoring system to their own patient cohort, patients without negative predictive factors reached a median OS of 13.7 months, comparable to other salvage Y-90 SIRT series. In a more recent study, Kurilova et al. [104] sought to create a normogram including 6 preprocedural parameters to predict liver PFS and OS outcomes in chemo-refractory patients undergoing Y-90 SIRT. One-hundred and three patients with chemo-refractory CRLM who underwent Y-90 SIRT were included in this retrospective analysis. With a median follow-up time of 9.0 months, reported median liver PFS and OS were 4 and 11.3 months, respectively. Pertaining to predictive factors associated with an increased liver PFS, only baseline standard uptake value (SUVmax), a metabolic tumor marker determined on PET-CT, was found to be significant. The 6 predictive parameters significantly associated with increased OS were baseline CEA levels, baseline alanine aminotransferase (ALT) levels, albumin level, sum of sizes of the two largest CRLM diameters in the treatment region, number of extrahepatic disease sites and tumor differentiation level. After each significant factor was assigned points according to each hazard ratio, one-year OS of patients with $<25$ points indicated a $90 \%$ chance of 1 -year survival, whereas total sum of points $>80$ estimated a $10 \%$ chance of 1-year survival. Shady et al. [98] compared different metrics of metabolic response (SUVmax, SUVpeak, metabolic tumor volume (MTV) and total lesion glycolysis (TLG)) on 18-fluorodeoxyglucose (FDG)-PET imaging to determine its prognostication value in treatment response and OS. In this retrospective review, forty-nine patients with 119 target tumors were treated with resin Y-90 SIRT in a salvage setting. The different metrics were calculated at baseline and on the first follow-up PET/CT studies after Y-90 SIRT treatment to determine whether patients were either responders or non-responders to treatment. With an overall median OS of 12.7 months, univariate analysis showed that early metabolic response (when determined by MTV and TLG) significantly predicted an improved OS.

The significance of genomic mutations as independent predictors of OS in chemorefractory CRLM patients undergoing Y-90 SIRT have also been evaluated. A retrospective study by Lahti et al. [105] evaluated the outcomes of 104 consecutive chemo-refractory CRLM patients with documented Kirsten rat sarcoma (KRAS) mutation status prior to undergoing resin Y-90 SIRT treatment. Most patients (84.6\%) had failed at least 2 prior lines of systemic chemotherapy, with a small portion of patients having progressed despite other liver-directed therapies such as prior HAIC (16.3\%) and TACE (8.7\%). KRAS mutations were identified in $45(43.3 \%)$ patients and median OS in mutant KRAS patients was approximately half that of wild-type (wt) KRAS patients (4.8 months vs. 9.5 months, respectively). Multivariate Cox regression analysis demonstrated mutant KRAS status to be an independent, negative predictor of OS in this cohort of patients, amongst other factors such as a worse Childs-Pugh score, higher baseline CEA level and no further systemic chemotherapy after Y-90 SIRT. One potential explanation for this result may be due to the intrinsic radio-resistance specific to KRAS mutated cell lines, which has been extensively researched in various other types of cancers where KRAS mutations are also prevalent. However, KRAS mutant CRC patients are also more likely to develop lung, brain and bone metastasis [106], and as such, it is unclear whether this may just be a reflection of a more 
aggressive biological process and advanced disease in these patients. In a similar study, Dabrowiecki et al. [107] evaluated 58 patients with known genomic analysis treated with resin Y-90 SIRT after progression of disease on at least one prior line of systemic chemotherapy. Whilst overall median OS in this study was calculated from time of diagnosis of hepatic metastasis, rather than from first Y-90 SIRT treatment, patients with CRLM without genomic mutation (mitogen-activated protein kinase (MAPK) wild-type) had prolonged OS compared to those patients with any type of mutation (median OS of $36.6 \mathrm{vs.} 23.7$ months, $p=0.02$ ). Also, there was a significantly prolonged OS in patients receiving Y-90 SIRT after failing one line of prior systemic chemotherapy vs. patients receiving Y-90 SIRT after failing multiple lines of chemotherapy (median OS of 46.3 vs. 26.6 months, $p=0.005$ ), thus conferring a potential survival advantage when Y-90 SIRT is administered earlier in chemo-refractory patients.

\subsection{Evidence for $Y-90$ in the First-Line Setting}

In 2004, van Hazel et al. [100] performed a small RCT involving 21 chemo-naïve patients with unresectable CRLM, comparing Y-90 SIRT and systemic chemotherapy (5FU/leucovorin) with systemic chemotherapy alone. The study showed a significant improvement in RR in the Y-90 SIRT combination arm compared to chemotherapy-alone arm (PR $73 \%$ vs. $0 \%, p<0.001$ ), as well as improved PFS (18.6 vs. 3.6 months, $p<0.0005$ ) and improved median OS (29.4 vs. 12.8 months, $p=0.02)$. Although the numbers of this study were small, the results were promising and acted as a precursor to larger phase III RCTs to investigate PFS and OS as primary endpoints.

The SIRFLOX, FOXFIRE and FOXFIRE-Global phase III RCTs were performed to evaluate the benefit of Y-90 SIRT in the first-line setting in conjunction with systemic chemotherapy (FOLFOX) in patients with unresectable CRLM [108-110]. The studies were performed in 14 countries, included a total of 1103 patients (randomized to either Y-90 SIRT and FOLFOX or FOLFOX alone \pm biological agents) and were designed for a combined analysis of OS [101]. The pooled results showed that whilst there was significant improvement in liver disease control in the Y-90 SIRT combination arm, this did not translate to a significant improved PFS (11 vs. 10.3 months) or median OS (22.6 vs. 23.3 months). The authors thus concluded that the use of Y-90 SIRT in conjunction with systemic chemotherapy as first-line treatment in patients with liver-only or liver-dominant CRLM could not be recommended in unselected patients. Possible reasons for this outcome could be partly explained by the high proportion of patients $(54 \%)$ who developed first progression at an extrahepatic site, as Y-90 SIRT would only act to treat liver disease. Also, $40 \%$ of patients in the SIRFLOX trial had limited extrahepatic disease at baseline. Further, crossover was allowed and anticipated where $12 \%$ of patients randomized to FOLFOX alone received Y-90 SIRT at a later line of therapy and $8 \%$ of patients assigned to Y-90 SIRT did not receive treatment due to unsuitability, only after randomization. Together, these factors could have also affected the primary endpoint. Others have raised concerns over the technical aspects of Y-90 SIRT used in these trials, including lack of treatment details (e.g., net administered activity, residual activity after administration, treated target volumes and lung shunts) and inadequate dose optimization [111], with the caveat that this may not have affected the large proportion of patients who developed extrahepatic progression as the first site of progressive disease. Interestingly, in a separate analysis of the SIRFLOX and FOXFIRE-Global trials, Gibbs et al. [112] showed that patients with right-side primary (RSP) tumors benefited from Y-90 SIRT, demonstrating a significantly improved OS of 4.9 months (median, 22 vs. 17.1 months, Y-90 SIRT combination arm vs. chemotherapy alone, $p=0.008$ ) when compared to patients with a left-side primary (LSP) tumor ( $24.6 \mathrm{vs}$. 26.6 months, $p=0.264$ ). This consistent gain in OS was demonstrated in both trials (SIRFLOX, 4.8 months gain and FOXFIRE-GLOBAL, 7.9 months gain), suggesting that this result was not related to a consequence of a change imbalance of prognostic factors. Furthermore, multivariate analysis into factors impacting OS in RSP patients showed that treatment with Y-90 SIRT remained statistically significant. Whilst the authors concluded that there was a lack of a 
full biological understanding for this side-dependent difference, one potential explanation may be that more aggressive, initial systemic therapies (e.g., triplet chemotherapy regimen with bevacizumab) used in the first-line setting could be having a greater impact in this cohort of patients who already have a known poorer prognosis $[113,114]$ when compared to patients with LSP tumors. However, given that many patients may not be fit for a triplet chemotherapy regimen and given the lack of survival benefit with EGFR inhibitors in certain patients with RSP tumors (RAS wild-type tumors) [114], there may be a potential role for the inclusion of Y-90 SIRT as part of first-line treatment in certain patients with RSP tumors with liver-only or liver-dominant metastatic disease. Further studies evaluating the impact of Y-90 SIRT on primary tumor side, as well as other potential drivers of side-based differences in patients with metastatic CRC, is warranted.

An important secondary objective in the clinical trials was to determine the impact of Y-90 SIRT and FOLFOX on QoL compared to patients on FOLFOX alone. The results of a QoL study on the combined trials [115] demonstrated an initial, significantly worse QoL in the combination Y-90 SIRT and FOLFOX arm when compared to the FOLFOX arm alone, up to 3 months after Y-90 SIRT administration, although these changes did not reach thresholds for clinical importance. Whilst patients in the Y-90 SIRT combination arm experienced more fatigue, which is a common side effect of Y-90 SIRT, this cohort of patients experienced significantly lower levels of other side effects seen in the FOLFOX alone group (e.g., sore mouth/tongue and peripheral neuropathy), likely due to a dose reduction of oxaliplatin mandated for three cycles for patients in the Y-90 SIRT combination arm. After the initial 3-month period after Y-90 SIRT, there were no clinically significant differences in QoL between the two study arms. Overall, the study concluded that there was no significant detriment in QoL after the initial 3 months post-Y-90 SIRT that were deemed clinically significant.

\subsection{Y-90 SIRT in The Neoadjuvant Setting (Radiation Lobectomy and Radiation Segmentectomy)}

In patients with initially unresectable CRLM, shrinkage of tumorous tissue and disengaging it from vital structures can increase the chance of the patient being converted to hepatic resection [116]. Another critical factor is for patients to have an adequate future liver remnant (FLR) volume to avoid liver failure and death post-hepatectomy. When an adequate FLR is lacking, several preoperative measures can be performed to improve liver reserves and contralateral hypertrophy to allow for safe hepatic resection [117]. These include Y-90 SIRT, portal vein embolization (PVE) and associating liver partition with portal vein ligation (PVL) for staged hepatectomy (ALPPS) [118-120]. Y-90 SIRT, when used in this setting, is also termed radiation lobectomy (RL), which was first described by Siddiqi et al. in 2009 as a palliative treatment for CLRM [121]. In distinction to conventional Y-90 SIRT treatment, RL delivers an intentionally higher 'ablative' radiation dose (at least $120 \mathrm{~Gy}$ ) to both tumor and adjacent liver parenchyma. The benefit of this is two-fold; firstly, this has the benefit of being able to offer local tumor control to the treated side, while simultaneously permitting contralateral lobe FLR hypertrophy, and secondly, as the FLR hypertrophy usually occurs over several months after RL, this allows a biological test of time to assess disease progression, thus preventing morbidity from unnecessary hepatectomy. If the FLR hypertrophy is insufficient after RL, this also does not preclude the patient from undergoing future subsequent procedures to induce further contralateral hypertrophy. In a recent systematic review [122] of 16 studies comprising 602 patients, evaluating contralateral liver hypertrophy and oncological outcomes following RL, the median kinetic growth rate per week of the contralateral liver lobe was $0.7 \%$, with the maximum degree of contralateral hypertrophy exceeding $40 \%$ achieved after 9 months. Further, reported local tumor control was $84 \%$, with CTR achieved in $30 \%$ of patients. Moreover, a recent secondary analysis [123] of the SIRFLOX study patient cohort revealed a higher resectability rate in the Y-90 SIRT and FOLFOX arm compared to the FOLFOX arm alone $(38.1 \%$ vs. $28.9 \%, p<0.001)$, lamenting its downstaging potential. 
In patients with limited unresectable CRLM, aggressive local disease control via ablative techniques in addition to systemic chemotherapy have shown a PFS and OS benefit when compared to patients treated with systemic chemotherapy alone, as demonstrated in the CLOCC (Chemotherapy and Bevacizumab With or Without Radiofrequency Ablation in Treating Unresectable Liver Metastases in Patients With Colorectal Cancer) trial [124]. In this regard, radiation segmentectomy (RS) is a potentially useful technique in patients with tumors localized to 1 or 2 segments of the liver, that are unsuitable for ablation or resection, either due to large tumor size or an unfavorable anatomical location. The concept of RS involves delivering a high 'ablative' dose of radiation to the involved tumor segments, resulting in tumor eradication while confining the radiation effects only to the segments infused [85,125]. Via this technique, median tumor dose can reach up to $1200 \mathrm{~Gy}$, resulting in a high degree of histological necrosis and objective RR of up to $86 \%$ (according to WHO and EASL [European Association for the Study of the Liver] criteria) $[125,126]$. While most data published on RS is mainly in the context of HCC, several small studies have shown promising results in the context of CRLM. In a small, single-center study of 10 patients by Meiers et al. [127], RS was performed for 10 patients with hepatic metastasis (seven of which were CRLM) deemed unfit or ablation or surgery. With a mean tumor dose of $261 \mathrm{~Gy}$, five out of ten patients showed a complete metabolic response according to PET response criteria in solid tumors (PERCIST), with a mean PFS of 7.1 months. In a separate study by Kurilova et al. [128], 10 patients with 14 CRLM underwent RS, demonstrating a response rate of $100 \%$ and $44 \%$ according to the per Choi and RECIST 1.1 criteria, respectively. With a median deliver dose of $293 \mathrm{~Gy}$, reported median OS in this small cohort was 41.5 months, with a 2-year local tumor control rate of $83 \%$. In short, the concept of RS in the context of CRLM is still in its infancy, although initial results on safety and efficacy are encouraging and it serves a potential role in patients with limited liver metastatic disease unamenable to surgery or local ablative techniques.

\subsection{Complications of $Y-90$ SIRT}

In general, Y-90 SIRT is safe and well-tolerated, although there are specific complications related to this therapy worth mentioning. Similar to TACE, post-Y-90 SIRT patients can develop a post-radioembolization syndrome (incidence 20-70\%), which can manifest as fatigue, nausea, vomiting, transient liver dysfunction, abdominal discomfort, cachexia and fever up to 2 weeks after the procedure [129]. This is akin to post-embolization syndrome commonly seen in post-TACE patients, although usually milder in severity and usually does not require hospitalization [89]. The effects of aberrant radioactive microspheres depositing elsewhere besides the liver can result in gastrointestinal ulceration $(<5 \%)$ which can be severe, cholecystitis $(<1 \%)$, pancreatitis $(<1 \%)$ and radiation dermatitis (usually via the falciform artery supplying the anterior abdominal wall, $<1 \%$ ). Biliary complications can occur in up to $10 \%$ of patients, and whilst the majority of patients may be asymptomatic, this can present as cholangitis, stricture formation or biloma secondary to biliary necrosis. The rate of biliary complications is also significantly higher in patients with a hepaticojejunostomy or prior instrumentation to the ampulla of Vater [130]. Radiation pneumonitis has been described in patients with a high LSF $(>13 \%)$ developing restrictive ventilatory dysfunction post-Y-90 SIRT, although the incidence of this is rare $(<1 \%)$ using standard dosimetry models [130]. One of the most serious complications related to Y-90 SIRT is radiation-induced liver disease (RILD), due to excessive radiation dose to the liver parenchyma. This is reported in $0-4 \%$ of patients in the literature and in the most severe cases, can manifest as fulminant liver failure with jaundice and ascites, 4-8 weeks after treatment [130]. Factors associated with RILD are patients with pre-existing liver cirrhosis, baseline bilirubin levels more than $2 \mathrm{mg} / \mathrm{dL}$, single-session whole liver radioembolization and inaccurate dosimetry calculations. 


\section{Conclusions}

The management of CRLM remains a major challenge despite the constantly evolving landscape of improving loco-regional and systemic therapies. Currently, in appropriate patients with chemo-refractory disease with liver-only or liver-dominant metastatic disease, guidelines recommend considering the use of hepatic-directed IATs [13,14]. In chemorefractory patients, systemic treatment options are limited, providing a median OS of 4-6 months when compared to best supportive care [96,97]. As such, in this select cohort of patients, it would seem reasonable to consider liver-directed IATs to provide local disease control and to prolong OS. However, most available data in the literature is based either on retrospective series or small, prospective phase I/II trials, with few large-scale RCTs available in the literature, which are desperately needed to increase the robustness of the data to support these therapies in this setting. Moreover, unlike systemic chemotherapeutic regimens which have a broad treatment algorithm, there is currently little consensus on the optimal role, choice of IAT and timing for use within this cohort of patients. To date, there have been two systemic reviews which have tried to address this issue [131,132], although in both instances, due to significant heterogeneity encountered in the available literature, this precluded a meaningful comparison between the different IATs and evidence supporting one over the other, and optimal timing for use is still lacking. Two small retrospective studies have also compared the effectiveness of HAIC vs. Y-90 SIRT in unresectable, pretreated CRLM $[133,134]$. Despite one of the studies [133] suggesting HAIC to be associated with a better OS when compared to Y-90 SIRT, it is noteworthy that this is most likely related to lead time bias, as when examining the two groups, it is apparent that Y-90 SIRT was likely offered at a later time during the natural history of the disease when compared to HAIC. Further, the difference in OS is only apparent upon diagnosis of 'isolated, unresectable CRLM', a rather random time point of assessment, with no significant OS difference from time of stage 4 diagnosis between the HAIC and Y-90 SIRT group. In short, it is difficult to draw any significant conclusions from this particular study. It is thus likely that the current choice of IAT would highly depend on the technical expertise available, as well as cost considerations in certain countries. There has also been increasing enthusiasm in expanding the role of IATs earlier in the course of disease as an addition to systemic chemotherapy to intensity treatment response, either in the first-line setting in conjunction with systemic treatment, or with the aim of potential downstaging for surgical resection. In recent years, the largest study in the field of interventional oncology pertaining to the use of Y-90 SIRT in the first-line setting in conjunction with systemic chemotherapy [101] wielded disappointing results with an absence of OS benefit, and as such, was not recommended in unselected patients with metastatic CRC. In this regard, it is likely that Y-90 SIRT would still provide the most benefit in the treatment of chemo-refractory patients. Future directions in this field would include large-scale, multi-center RCTs comparing IATs with concurrent systemic chemotherapy to systemic chemotherapy alone, as well as direct comparison between IATs with a strict patient selection criterion and specified clinical outcomes. Finally, future research would also include the investigation on the impact of genetic determinants on treatment response with the aim of identifying optimal treatment populations that would benefit most from these therapies.

Author Contributions: Conceptualization, U.P.; writing—original draft preparation, J.K. and U.P.; writing-review and editing, J.K. and U.P. All authors have read and agreed to the published version of the manuscript.

Funding: This research received no external funding.

Conflicts of Interest: The authors declare no conflict of interest. 


\section{References}

1. Siegel, R.L.; Miller, K.D.; Jemal, A. Cancer statistics, 2019. CA Cancer J. Clin. 2019, 69, 7-34. [CrossRef]

2. Weiss, L.; Grundmann, E.; Torhorst, J.; Hartveit, F.; Moberg, I.; Eder, M.; Fenoglio-Preiser, C.M.; Napier, J.; Horne, C.H.; Lopez, M.J.; et al. Haematogenous metastatic patterns in colonic carcinoma: An analysis of 1541 necropsies. J. Pathol. 1986, 150, 195-203. [CrossRef] [PubMed]

3. Riihimäki, M.; Hemminki, A.; Sundquist, J.; Hemminki, K. Patterns of metastasis in colon and rectal cancer. Sci. Rep. 2016, 6, 29765. [CrossRef]

4. Abbas, S.; Lam, V.; Hollands, M. Ten-Year Survival after Liver Resection for Colorectal Metastases: Systematic Review and Meta-Analysis. ISRN Oncol. 2011, 2011, 763245. [CrossRef] [PubMed]

5. Tomlinson, J.S.; Jarnagin, W.R.; DeMatteo, R.P.; Fong, Y.; Kornprat, P.; Gonen, M.; Kemeny, N.; Brennan, M.F.; Blumgart, L.H.; D'Angelica, M. Actual 10-year survival after resection of colorectal liver metastases defines cure. J. Clin. Oncol. 2007, 25, 4575-4580. [CrossRef]

6. Devaud, N.; Kanji, Z.S.; Dhani, N.; Grant, R.C.; Shoushtari, H.; Serrano, P.E.; Nanji, S.; Greig, P.D.; McGilvray, I.; Moulton, C.A.; et al. Liver resection after chemotherapy and tumour downsizing in patients with initially unresectable colorectal cancer liver metastases. HPB Oxf. 2014, 16, 475-480. [CrossRef]

7. Adam, R.; Wicherts, D.A.; de Haas, R.J.; Ciacio, O.; Lévi, F.; Paule, B.; Ducreux, M.; Azoulay, D.; Bismuth, H.; Castaing, D. Patients with initially unresectable colorectal liver metastases: Is there a possibility of cure? J. Clin. Oncol. 2009, 27, 1829-1835. [CrossRef] [PubMed]

8. Jones, R.P.; Jackson, R.; Dunne, D.F.; Malik, H.Z.; Fenwick, S.W.; Poston, G.J.; Ghaneh, P. Systematic review and meta-analysis of follow-up after hepatectomy for colorectal liver metastases. Br. J. Surg. 2012, 99, 477-486. [CrossRef] [PubMed]

9. Yamazaki, K.; Nagase, M.; Tamagawa, H.; Ueda, S.; Tamura, T.; Murata, K.; Eguchi Nakajima, T.; Baba, E.; Tsuda, M.; Moriwaki, T.; et al. Randomized phase III study of bevacizumab plus FOLFIRI and bevacizumab plus mFOLFOX6 as first-line treatment for patients with metastatic colorectal cancer (WJOG4407G). Ann. Oncol. 2016, 27, 1539-1546. [CrossRef] [PubMed]

10. Loupakis, F.; Cremolini, C.; Masi, G.; Lonardi, S.; Zagonel, V.; Salvatore, L.; Cortesi, E.; Tomasello, G.; Ronzoni, M.; Spadi, R.; et al. Initial Therapy with FOLFOXIRI and Bevacizumab for Metastatic Colorectal Cancer. N. Eng. J. Med. 2014, 371, 1609-1618. [CrossRef] [PubMed]

11. Breedis, C.; Young, G. The blood supply of neoplasms in the liver. Am. J. Pathol. 1954, 30, 969-977. [PubMed]

12. Ackerman, N.B. The blood supply of experimental liver metastases. IV. Changes in vascularity with increasing tumor growth. Surgery 1974, 75, 589-596. [PubMed]

13. National Comprehensive Cancer Network. Colon Cancer (Version 1.2021). Available online: https://www.nccn.org/ professionals/physician_gls/pdf/colon.pdf (accessed on 25 December 2020).

14. Van Cutsem, E.; Cervantes, A.; Adam, R.; Sobrero, A.; Van Krieken, J.H.; Aderka, D.; Aranda Aguilar, E.; Bardelli, A.; Benson, A.; Bodoky, G.; et al. ESMO consensus guidelines for the management of patients with metastatic colorectal cancer. Ann. Oncol. 2016, 27, 1386-1422. [CrossRef]

15. Gray, B.; Van Hazel, G.; Hope, M.; Burton, M.; Moroz, P.; Anderson, J.; Gebski, V. Randomised trial of SIR-Spheres plus chemotherapy vs. chemotherapy alone for treating patients with liver metastases from primary large bowel cancer. Ann. Oncol. 2001, 12, 1711-1720. [CrossRef]

16. Hendlisz, A.; Van den Eynde, M.; Peeters, M.; Maleux, G.; Lambert, B.; Vannoote, J.; De Keukeleire, K.; Verslype, C.; Defreyne, L.; Van Cutsem, E.; et al. Phase III trial comparing protracted intravenous fluorouracil infusion alone or with yttrium-90 resin microspheres radioembolization for liver-limited metastatic colorectal cancer refractory to standard chemotherapy. J. Clin. Oncol. 2010, 28, 3687-3694. [CrossRef]

17. Teo, J.Y.; Allen, J.C., Jr.; Ng, D.C.; Choo, S.P.; Tai, D.W.; Chang, J.P.; Cheah, F.K.; Chow, P.K.; Goh, B.K. A systematic review of contralateral liver lobe hypertrophy after unilobar selective internal radiation therapy with Y90. HPB Oxf. 2016, 18, 7-12. [CrossRef]

18. Dizon, D.S.; Schwartz, J.; Kemeny, N. Regional chemotherapy: A focus on hepatic artery infusion for colorectal cancer liver metastases. Surg. Oncol. Clin. N. Am. 2008, 17, 759-771. [CrossRef]

19. Ducreux, M.; Ychou, M.; Laplanche, A.; Gamelin, E.; Lasser, P.; Husseini, F.; Quenet, F.; Viret, F.; Jacob, J.H.; Boige, V.; et al. Hepatic arterial oxaliplatin infusion plus intravenous chemotherapy in colorectal cancer with inoperable hepatic metastases: A trial of the gastrointestinal group of the Federation Nationale des Centres de Lutte Contre le Cancer. J. Clin. Oncol. 2005, 23, 4881-4887. [CrossRef]

20. van Riel, J.M.; van Groeningen, C.J.; de Greve, J.; Gruia, G.; Pinedo, H.M.; Giaccone, G. Continuous infusion of hepatic arterial irinotecan in pretreated patients with colorectal cancer metastatic to the liver. Ann. Oncol. 2004, 15, 59-63. [CrossRef]

21. Fiorentini, G.; Rossi, S.; Dentico, P.; Bernardeschi, P.; Calcinai, A.; Bonechi, F.; Cantore, M.; Guadagni, S.; De Simone, M. Irinotecan hepatic arterial infusion chemotherapy for hepatic metastases from colorectal cancer: A phase II clinical study. Tumori 2003, 89, 382-384. [CrossRef]

22. Del Freo, A.; Fiorentini, G.; Sanguinetti, F.; Muttini, M.P.; Pennucci, C.; Mambrini, A.; Pacetti, P.; Della Seta, R.; Lombardi, M.; Torri, T.; et al. Hepatic arterial chemotherapy with oxaliplatin, folinic acid and 5-fluorouracil in pre-treated patients with liver metastases from colorectal cancer. In Vivo 2006, 20, 743-746. 
23. Mahnken, A.H.; Pereira, P.L.; Baère, T.d. Interventional Oncologic Approaches to Liver Metastases. Radiology 2013, 266, 407-430. [CrossRef]

24. Deschamps, F.; Rao, P.; Teriitehau, C.; Hakime, A.; Malka, D.; Boige, V.; Ducreux, M.; Elias, D.; Goere, D.; de Baere, T. Percutaneous femoral implantation of an arterial port catheter for intraarterial chemotherapy: Feasibility and predictive factors of long-term functionality. J. Vasc. Interv. Radiol. 2010, 21, 1681-1688. [CrossRef]

25. Karanicolas, P.J.; Metrakos, P.; Chan, K.; Asmis, T.; Chen, E.; Kingham, T.P.; Kemeny, N.; Porter, G.; Fields, R.C.; Pingpank, J.; et al. Hepatic arterial infusion pump chemotherapy in the management of colorectal liver metastases: Expert consensus statement. Curr. Oncol. 2014, 21, e129. [CrossRef]

26. Datta, J.; Narayan, R.R.; Kemeny, N.E.; D'Angelica, M.I. Role of Hepatic Artery Infusion Chemotherapy in Treatment of Initially Unresectable Colorectal Liver Metastases: A Review. JAMA Surg. 2019, 154, 768-776. [CrossRef]

27. Kemeny, N.; Gonen, M.; Sullivan, D.; Schwartz, L.; Benedetti, F.; Saltz, L.; Stockman, J.; Fong, Y.; Jarnagin, W.; Bertino, J.; et al. Phase I study of hepatic arterial infusion of floxuridine and dexamethasone with systemic irinotecan for unresectable hepatic metastases from colorectal cancer. J. Clin. Oncol. 2001, 19, 2687-2695. [CrossRef]

28. Kemeny, N.; Jarnagin, W.; Paty, P.; Gönen, M.; Schwartz, L.; Morse, M.; Leonard, G.; D'Angelica, M.; DeMatteo, R.; Blumgart, L.; et al. Phase I trial of systemic oxaliplatin combination chemotherapy with hepatic arterial infusion in patients with unresectable liver metastases from colorectal cancer. J. Clin. Oncol. 2005, 23, 4888-4896. [CrossRef]

29. Kemeny, N.E.; Melendez, F.D.; Capanu, M.; Paty, P.B.; Fong, Y.; Schwartz, L.H.; Jarnagin, W.R.; Patel, D.; D’Angelica, M. Conversion to resectability using hepatic artery infusion plus systemic chemotherapy for the treatment of unresectable liver metastases from colorectal carcinoma. J. Clin. Oncol. 2009, 27, 3465-3471. [CrossRef]

30. Goéré, D.; Deshaies, I.; de Baere, T.; Boige, V.; Malka, D.; Dumont, F.; Dromain, C.; Ducreux, M.; Elias, D. Prolonged survival of initially unresectable hepatic colorectal cancer patients treated with hepatic arterial infusion of oxaliplatin followed by radical surgery of metastases. Ann. Surg. 2010, 251, 686-691. [CrossRef]

31. Lévi, F.; Karaboué, A.; Gorden, L.; Innominato, P.F.; Saffroy, R.; Giacchetti, S.; Hauteville, D.; Guettier, C.; Adam, R.; Bouchahda, M. Cetuximab and circadian chronomodulated chemotherapy as salvage treatment for metastatic colorectal cancer (mCRC): Safety, efficacy and improved secondary surgical resectability. Cancer Chemother Pharmacol. 2011, 67, 339-348. [CrossRef]

32. Lévi, F.A.; Boige, V.; Hebbar, M.; Smith, D.; Lepère, C.; Focan, C.; Karaboué, A.; Guimbaud, R.; Carvalho, C.; Tumolo, S.; et al. Conversion to resection of liver metastases from colorectal cancer with hepatic artery infusion of combined chemotherapy and systemic cetuximab in multicenter trial OPTILIV. Ann. Oncol. 2016, 27, 267-274. [CrossRef]

33. Cercek, A.; Boucher, T.M.; Gluskin, J.S.; Aguiló, A.; Chou, J.F.; Connell, L.C.; Capanu, M.; Reidy-Lagunes, D.; D'Angelica, M.; Kemeny, N.E. Response rates of hepatic arterial infusion pump therapy in patients with metastatic colorectal cancer liver metastases refractory to all standard chemotherapies. J. Surg. Oncol. 2016, 114, 655-663. [CrossRef]

34. Pak, L.M.; Kemeny, N.E.; Capanu, M.; Chou, J.F.; Boucher, T.; Cercek, A.; Balachandran, V.P.; Kingham, T.P.; Allen, P.J.; DeMatteo, R.P.; et al. Prospective phase II trial of combination hepatic artery infusion and systemic chemotherapy for unresectable colorectal liver metastases: Long term results and curative potential. J. Surg. Oncol. 2018, 117, 634-643. [CrossRef]

35. Ducreux, M.; Innominato, P.F.; Hebbar, M.; Smith, D.M.; Lepère, C.; Focan, C.N.J.; Guimbaud, R.; Carvalho, C.; Tumolo, S.; Awad, S.; et al. Hepatic artery infusion (HAI) of irinotecan, 5-fluorouracil, and oxaliplatin plus intravenous cetuximab (Cet) (Optiliv) after failure on one versus two or three chemotherapy protocols in patients (pts) with unresectable liver metastases from wt KRAS colorectal cancer (LM-CRC) (European phase II clinical trial NCT00852228). J. Clin. Oncol. 2013, 31, 3599. [CrossRef]

36. Nelson, R.; Freels, S. Hepatic artery adjuvant chemotherapy for patients having resection or ablation of colorectal cancer metastatic to the liver. Cochrane Database Syst. Rev. 2006, Cd003770. [CrossRef] [PubMed]

37. Groot Koerkamp, B.; Sadot, E.; Kemeny, N.E.; Gönen, M.; Leal, J.N.; Allen, P.J.; Cercek, A.; DeMatteo, R.P.; Kingham, T.P.; Jarnagin, W.R.; et al. Perioperative Hepatic Arterial Infusion Pump Chemotherapy Is Associated With Longer Survival After Resection of Colorectal Liver Metastases: A Propensity Score Analysis. J. Clin. Oncol. 2017, 35, 1938-1944. [CrossRef] [PubMed]

38. Goéré, D.; Benhaim, L.; Bonnet, S.; Malka, D.; Faron, M.; Elias, D.; Lefèvre, J.H.; Deschamps, F.; Dromain, C.; Boige, V.; et al. Adjuvant chemotherapy after resection of colorectal liver metastases in patients at high risk of hepatic recurrence: A comparative study between hepatic arterial infusion of oxaliplatin and modern systemic chemotherapy. Ann. Surg. 2013, 257, 114-120. [CrossRef] [PubMed]

39. Goéré, D.; Pignon, J.P.; Gelli, M.; Elias, D.; Benhaim, L.; Deschamps, F.; Caramella, C.; Boige, V.; Ducreux, M.; de Baere, T.; et al. Postoperative hepatic arterial chemotherapy in high-risk patients as adjuvant treatment after resection of colorectal liver metastases-A randomized phase II/III trial-PACHA-01 (NCT02494973). BMC Cancer 2018, 18, 787. [CrossRef]

40. Buisman, F.E.; Homs, M.Y.V.; Grünhagen, D.J.; Filipe, W.F.; Bennink, R.J.; Besselink, M.G.H.; Borel Rinkes, I.H.M.; Bruijnen, R.C.G.; Cercek, A.; D'Angelica, M.I.; et al. Adjuvant hepatic arterial infusion pump chemotherapy and resection versus resection alone in patients with low-risk resectable colorectal liver metastases-The multicenter randomized controlled PUMP trial. BMC Cancer 2019, 19, 327. [CrossRef]

41. Allen, P.J.; Nissan, A.; Picon, A.I.; Kemeny, N.; Dudrick, P.; Ben-Porat, L.; Espat, J.; Stojadinovic, A.; Cohen, A.M.; Fong, Y.; et al. Technical complications and durability of hepatic artery infusion pumps for unresectable colorectal liver metastases: An institutional experience of 544 consecutive cases. J. Am. Coll. Surg. 2005, 201, 57-65. [CrossRef] 
42. Deschamps, F.; Elias, D.; Goere, D.; Malka, D.; Ducreux, M.; Boige, V.; Auperin, A.; de Baere, T. Intra-arterial hepatic chemotherapy: A comparison of percutaneous versus surgical implantation of port-catheters. Cardiovasc. Interv. Radiol. 2011, 34, 973-979. [CrossRef]

43. Arai, Y.; Aoyama, T.; Inaba, Y.; Okabe, H.; Ihaya, T.; Kichikawa, K.; Ohashi, Y.; Sakamoto, J.; Oba, K.; Saji, S. Phase II study on hepatic arterial infusion chemotherapy using percutaneous catheter placement techniques for liver metastases from colorectal cancer (JFMC28 study). Asia Pac. J. Clin. Oncol. 2015, 11, 41-48. [CrossRef]

44. Barnett, K.T.; Malafa, M.P. Complications of hepatic artery infusion: A review of 4580 reported cases. Int. J. Gastrointest Cancer 2001, 30, 147-160. [CrossRef]

45. Power, D.G.; Kemeny, N.E. The role of floxuridine in metastatic liver disease. Mol. Cancer Ther. 2009, 8, 1015-1025. [CrossRef] [PubMed]

46. Kanat, O.; Gewirtz, A.; Kemeny, N. What is the potential role of hepatic arterial infusion chemo-therapy in the current armamentorium against colorectal cancer. J. Gastrointest Oncol. 2012, 3, 130-138. [CrossRef]

47. Kemeny, N.; Seiter, K.; Niedzwiecki, D.; Chapman, D.; Sigurdson, E.; Cohen, A.; Botet, J.; Oderman, P.; Murray, P. A randomized trial of intrahepatic infusion of fluorodeoxyuridine with dexamethasone versus fluorodeoxyuridine alone in the treatment of metastatic colorectal cancer. Cancer 1992, 69, 327-334. [CrossRef]

48. Stagg, R.J.; Venook, A.P.; Chase, J.L.; Lewis, B.J.; Warren, R.S.; Roh, M.; Mulvihill, S.J.; Grobman, B.J.; Rayner, A.A.; Hohn, D.C. Alternating hepatic intra-arterial floxuridine and fluorouracil: A less toxic regimen for treatment of liver metastases from colorectal cancer. J. Natl. Cancer Inst. 1991, 83, 423-428. [CrossRef]

49. Vogel, A.; Cervantes, A.; Chau, I.; Daniele, B.; Llovet, J.M.; Meyer, T.; Nault, J.C.; Neumann, U.; Ricke, J.; Sangro, B.; et al. Hepatocellular carcinoma: ESMO Clinical Practice Guidelines for diagnosis, treatment and follow-up. Ann. Oncol. 2018, 29, iv238-iv255. [CrossRef] [PubMed]

50. Wáng, Y.X.; De Baere, T.; Idée, J.M.; Ballet, S. Transcatheter embolization therapy in liver cancer: An update of clinical evidences. Chin. J. Cancer Res. 2015, 27, 96-121. [CrossRef] [PubMed]

51. Pung, L.; Ahmad, M.; Mueller, K.; Rosenberg, J.; Stave, C.; Hwang, G.L.; Shah, R.; Kothary, N. The Role of Cone-Beam CT in Transcatheter Arterial Chemoembolization for Hepatocellular Carcinoma: A Systematic Review and Meta-analysis. J. Vasc. Interv. Radiol. 2017, 28, 334-341. [CrossRef] [PubMed]

52. Jin, B.; Wang, D.; Lewandowski, R.J.; Riaz, A.; Ryu, R.K.; Sato, K.T.; Larson, A.C.; Salem, R.; Omary, R.A. Chemoembolization endpoints: Effect on survival among patients with hepatocellular carcinoma. Am. J. Roentgenol. 2011, 196, 919-928. [CrossRef] [PubMed]

53. Chow, F.C.; Chok, K.S. Colorectal liver metastases: An update on multidisciplinary approach. World J. Hepatol. 2019, 11, 150-172. [CrossRef] [PubMed]

54. Gruber-Rouh, T.; Marko, C.; Thalhammer, A.; Nour-Eldin, N.E.; Langenbach, M.; Beeres, M.; Naguib, N.N.; Zangos, S.; Vogl, T.J. Current strategies in interventional oncology of colorectal liver metastases. Br. J. Radiol. 2016, 89, 20151060. [CrossRef] [PubMed]

55. Wang, D.S.; Louie, J.D.; Sze, D.Y. Intra-arterial therapies for metastatic colorectal cancer. Semin Interv. Radiol. 2013, 30, 12-20. [CrossRef]

56. Hunt, T.M.; Flowerdew, A.D.; Birch, S.J.; Williams, J.D.; Mullee, M.A.; Taylor, I. Prospective randomized controlled trial of hepatic arterial embolization or infusion chemotherapy with 5-fluorouracil and degradable starch microspheres for colorectal liver metastases. Br. J. Surg. 1990, 77, 779-782. [CrossRef] [PubMed]

57. Eyol, E.; Boleij, A.; Taylor, R.R.; Lewis, A.L.; Berger, M.R. Chemoembolisation of rat colorectal liver metastases with drug eluting beads loaded with irinotecan or doxorubicin. Clin. Exp. Metastasis 2008, 25, 273-282. [CrossRef]

58. Tanaka, T.; Nishiofuku, H.; Maeda, S.; Masada, T.; Anai, H.; Sakaguchi, H.; Kichikawa, K. Repeated bland-TAE using small microspheres injected via an implantable port-catheter system for liver metastases: An initial experience. Cardiovasc. Interv. Radiol. 2014, 37, 493-497. [CrossRef]

59. Bonomo, G.; Della Vigna, P.; Monfardini, L.; Orgera, G.; Chiappa, A.; Bianchi, P.P.; Zampino, M.G.; Orsi, F. Combined therapies for the treatment of technically unresectable liver malignancies: Bland embolization and radiofrequency thermal ablation within the same session. Cardiovasc. Interv. Radiol. 2012, 35, 1372-1379. [CrossRef]

60. Gruber-Rouh, T.; Naguib, N.N.; Eichler, K.; Ackermann, H.; Zangos, S.; Trojan, J.; Beeres, M.; Harth, M.; Schulz, B.; Nour-Eldin, A.N.; et al. Transarterial chemoembolization of unresectable systemic chemotherapy-refractory liver metastases from colorectal cancer: Long-term results over a 10-year period. Int. J. Cancer 2014, 134, 1225-1231. [CrossRef]

61. Albert, M.; Kiefer, M.V.; Sun, W.; Haller, D.; Fraker, D.L.; Tuite, C.M.; Stavropoulos, S.W.; Mondschein, J.I.; Soulen, M.C. Chemoembolization of colorectal liver metastases with cisplatin, doxorubicin, mitomycin $\mathrm{C}$, ethiodol, and polyvinyl alcohol. Cancer 2011, 117, 343-352. [CrossRef]

62. Müller, H.; Nakchbandi, V.; Chatzisavvidis, I.; von Voigt, C. Repetitive chemoembolization with melphalan plus intra-arterial immuno-chemotherapy within 5-fluorouracil and granulocyte-macrophage colony-stimulating factor (GM-CSF) as effective firstand second-line treatment of disseminated colorectal liver metastases. Hepatogastroenterology 2003, 50, 1919-1926. [PubMed]

63. Vogl, T.J.; Lahrsow, M.; Albrecht, M.H.; Hammerstingl, R.; Thompson, Z.M.; Gruber-Rouh, T. Survival of patients with nonresectable, chemotherapy-resistant colorectal cancer liver metastases undergoing conventional lipiodol-based transarterial chemoembolization (cTACE) palliatively versus neoadjuvantly prior to percutaneous thermal ablation. Eur. J. Radiol. 2018, 102, 138-145. [CrossRef] 
64. Yamakado, K.; Inaba, Y.; Sato, Y.; Yasumoto, T.; Hayashi, S.; Yamanaka, T.; Nobata, K.; Takaki, H.; Nakatsuka, A. Radiofrequency Ablation Combined with Hepatic Arterial Chemoembolization Using Degradable Starch Microsphere Mixed with Mitomycin C for the Treatment of Liver Metastasis from Colorectal Cancer: A Prospective Multicenter Study. Cardiovasc. Interv. Radiol. 2017, 40, 560-567. [CrossRef] [PubMed]

65. Martin, R.C.; Joshi, J.; Robbins, K.; Tomalty, D.; Bosnjakovik, P.; Derner, M.; Padr, R.; Rocek, M.; Scupchenko, A.; Tatum, C. Hepatic intra-arterial injection of drug-eluting bead, irinotecan (DEBIRI) in unresectable colorectal liver metastases refractory to systemic chemotherapy: Results of multi-institutional study. Ann. Surg. Oncol. 2011, 18, 192-198. [CrossRef]

66. Aliberti, C.; Fiorentini, G.; Muzzio, P.C.; Pomerri, F.; Tilli, M.; Dallara, S.; Benea, G. Trans-arterial chemoembolization of metastatic colorectal carcinoma to the liver adopting DC Bead ${ }^{\circledR}$, drug-eluting bead loaded with irinotecan: Results of a phase II clinical study. Anticancer Res. 2011, 31, 4581-4587. [PubMed]

67. Iezzi, R.; Marsico, V.A.; Guerra, A.; Cerchiaro, E.; Cassano, A.; Basso, M.; Devicienti, E.; Rodolfino, E.; Barone, C.; Bonomo, L. Trans-Arterial Chemoembolization with Irinotecan-Loaded Drug-Eluting Beads (DEBIRI) and Capecitabine in Refractory Liver Prevalent Colorectal Metastases: A Phase II Single-Center Study. Cardiovasc. Interv. Radiol. 2015, 38, 1523-1531. [CrossRef] [PubMed]

68. Fiorentini, G.; Sarti, D.; Nardella, M.; Inchingolo, R.; Nestola, M.; Rebonato, A.; Guadagni, S. Chemoembolization Alone or Associated With Bevacizumab for Therapy of Colorectal Cancer Metastases: Preliminary Results of a Randomized Study. In Vivo 2020, 34, 683-686. [CrossRef]

69. Fiorentini, G.; Aliberti, C.; Tilli, M.; Mulazzani, L.; Graziano, F.; Giordani, P.; Mambrini, A.; Montagnani, F.; Alessandroni, P.; Catalano, V.; et al. Intra-arterial infusion of irinotecan-loaded drug-eluting beads (DEBIRI) versus intravenous therapy (FOLFIRI) for hepatic metastases from colorectal cancer: Final results of a phase III study. Anticancer Res. 2012, 32, 1387-1395. [PubMed]

70. Martin, R.C., II; Scoggins, C.R.; Schreeder, M.; Rilling, W.S.; Laing, C.J.; Tatum, C.M.; Kelly, L.R.; Garcia-Monaco, R.D.; Sharma, V.R.; Crocenzi, T.S.; et al. Randomized controlled trial of irinotecan drug-eluting beads with simultaneous FOLFOX and bevacizumab for patients with unresectable colorectal liver-limited metastasis. Cancer 2015, 121, 3649-3658. [CrossRef]

71. Pernot, S.; Pellerin, O.; Artru, P.; Montérymard, C.; Smith, D.; Raoul, J.L.; De La Fouchardière, C.; Dahan, L.; Guimbaud, R.; Sefrioui, D.; et al. Intra-arterial hepatic beads loaded with irinotecan (DEBIRI) with mFOLFOX6 in unresectable liver metastases from colorectal cancer: A Phase 2 study. Br. J. Cancer 2020, 123, 518-524. [CrossRef]

72. Martin, R.C., II; Scoggins, C.R.; Tomalty, D.; Schreeder, M.; Metzger, T.; Tatum, C.; Sharma, V. Irinotecan drug-eluting beads in the treatment of chemo-naive unresectable colorectal liver metastasis with concomitant systemic fluorouracil and oxaliplatin: Results of pharmacokinetics and phase I trial. J. Gastrointest Surg. 2012, 16, 1531-1538. [CrossRef]

73. Richardson, A.J.; Laurence, J.M.; Lam, V.W. Transarterial chemoembolization with irinotecan beads in the treatment of colorectal liver metastases: Systematic review. J. Vasc. Interv. Radiol. 2013, 24, 1209-1217. [CrossRef]

74. Jones, R.P.; Malik, H.Z.; Fenwick, S.W.; Terlizzo, M.; O'Grady, E.; Stremitzer, S.; Gruenberger, T.; Rees, M.; Plant, G.; Figueras, J.; et al. PARAGON II-A single arm multicentre phase II study of neoadjuvant therapy using irinotecan bead in patients with resectable liver metastases from colorectal cancer. Eur. J. Surg. Oncol. 2016, 42, 1866-1872. [CrossRef] [PubMed]

75. Xing, M.; Kooby, D.A.; El-Rayes, B.F.; Kokabi, N.; Camacho, J.C.; Kim, H.S. Locoregional therapies for metastatic colorectal carcinoma to the liver-an evidence-based review. J. Surg. Oncol. 2014, 110, 182-196. [CrossRef] [PubMed]

76. Aliberti, C.; Carandina, R.; Sarti, D.; Pizzirani, E.; Ramondo, G.; Cillo, U.; Guadagni, S.; Fiorentini, G. Transarterial chemoembolization with DC Bead LUMI ${ }^{\mathrm{TM}}$ radiopaque beads for primary liver cancer treatment: Preliminary experience. Future Oncol. 2017, 13, 2243-2252. [CrossRef]

77. Yu, J.S.; Kim, K.W.; Jeong, M.G.; Lee, D.H.; Park, M.S.; Yoon, S.W. Predisposing factors of bile duct injury after transcatheter arterial chemoembolization (TACE) for hepatic malignancy. Cardiovasc. Interv. Radiol. 2002, 25, 270-274. [CrossRef] [PubMed]

78. de Baere, T.; Tselikas, L.; Boige, V.; Ducreux, M.; Malka, D.; Goéré, D.; Benahim, E.; Deschamps, F. Intra-arterial therapies for colorectal cancer liver metastases (radioembolization excluded). Bull. Cancer 2017, 104, 402-406. [CrossRef]

79. Vogl, T.J.; Lammer, J.; Lencioni, R.; Malagari, K.; Watkinson, A.; Pilleul, F.; Denys, A.; Lee, C. Liver, gastrointestinal, and cardiac toxicity in intermediate hepatocellular carcinoma treated with PRECISION TACE with drug-eluting beads: Results from the PRECISION V randomized trial. AJR Am. J. Roentgenol. 2011, 197, W562-W570. [CrossRef]

80. Emami, B.; Lyman, J.; Brown, A.; Coia, L.; Goitein, M.; Munzenrider, J.E.; Shank, B.; Solin, L.J.; Wesson, M. Tolerance of normal tissue to therapeutic irradiation. Int. J. Radiat.Oncol. Biol Phys. 1991, 21, 109-122. [CrossRef]

81. Lewandowski, R.J.; Geschwind, J.F.; Liapi, E.; Salem, R. Transcatheter intraarterial therapies: Rationale and overview. Radiology 2011, 259, 641-657. [CrossRef]

82. Campbell, A.M.; Bailey, I.H.; Burton, M.A. Tumour dosimetry in human liver following hepatic yttrium-90 microsphere therapy. Phys. Med. Biol. 2001, 46, 487-498. [CrossRef]

83. Gabr, A.; Kallini, J.R.; Gates, V.L.; Hickey, R.; Kulik, L.; Desai, K.; Thornburg, B.; Marshall, K.; Salzig, K.; Williams, M.; et al. Same-day (90)Y radioembolization: Implementing a new treatment paradigm. Eur. J. Nucl. Med. Mol. Imaging 2016, 43, $2353-2359$. [CrossRef]

84. Abdelmaksoud, M.H.; Louie, J.D.; Kothary, N.; Hwang, G.L.; Kuo, W.T.; Hofmann, L.V.; Hovsepian, D.M.; Sze, D.Y. Embolization of parasitized extrahepatic arteries to reestablish intrahepatic arterial supply to tumors before yttrium-90 radioembolization. $J$. Vasc. Interv. Radiol. 2011, 22, 1355-1362. [CrossRef] 
85. Boas, F.E.; Bodei, L.; Sofocleous, C.T. Radioembolization of Colorectal Liver Metastases: Indications, Technique, and Outcomes. J. Nucl. Med. 2017, 58, 104s-111s. [CrossRef] [PubMed]

86. Ahmadzadehfar, H.; Duan, H.; Haug, A.R.; Walrand, S.; Hoffmann, M. The role of SPECT/CT in radioembolization of liver tumours. Eur. J. Nucl. Med. Mol. Imaging 2014, 41 (Suppl. S1), S115-S124. [CrossRef]

87. van Hazel, G.A.; Pavlakis, N.; Goldstein, D.; Olver, I.N.; Tapner, M.J.; Price, D.; Bower, G.D.; Briggs, G.M.; Rossleigh, M.A.; Taylor, D.J.; et al. Treatment of fluorouracil-refractory patients with liver metastases from colorectal cancer by using yttrium-90 resin microspheres plus concomitant systemic irinotecan chemotherapy. J. Clin. Oncol. 2009, 27, 4089-4095. [CrossRef] [PubMed]

88. Saxena, A.; Meteling, B.; Kapoor, J.; Golani, S.; Morris, D.L.; Bester, L. Is yttrium-90 radioembolization a viable treatment option for unresectable, chemorefractory colorectal cancer liver metastases? A large single-center experience of 302 patients. Ann. Surg. Oncol. 2015, 22, 794-802. [CrossRef] [PubMed]

89. Kennedy, A.S.; Coldwell, D.; Nutting, C.; Murthy, R.; Wertman, D.E., Jr.; Loehr, S.P.; Overton, C.; Meranze, S.; Niedzwiecki, J.; Sailer, S. Resin 90Y-microsphere brachytherapy for unresectable colorectal liver metastases: Modern USA experience. Int. J. Radiat.Oncol. Biol. Phys. 2006, 65, 412-425. [CrossRef] [PubMed]

90. Cosimelli, M.; Golfieri, R.; Cagol, P.P.; Carpanese, L.; Sciuto, R.; Maini, C.L.; Mancini, R.; Sperduti, I.; Pizzi, G.; Diodoro, M.G.; et al. Multi-centre phase II clinical trial of yttrium-90 resin microspheres alone in unresectable, chemotherapy refractory colorectal liver metastases. Br. J. Cancer 2010, 103, 324-331. [CrossRef]

91. Sofocleous, C.T.; Garcia, A.R.; Pandit-Taskar, N.; Do, K.G.; Brody, L.A.; Petre, E.N.; Capanu, M.; Longing, A.P.; Chou, J.F.; Carrasquillo, J.A.; et al. Phase I trial of selective internal radiation therapy for chemorefractory colorectal cancer liver metastases progressing after hepatic arterial pump and systemic chemotherapy. Clin. Colorectal Cancer 2014, 13, 27-36. [CrossRef]

92. Sofocleous, C.T.; Violari, E.G.; Sotirchos, V.S.; Shady, W.; Gonen, M.; Pandit-Taskar, N.; Petre, E.N.; Brody, L.A.; Alago, W.; Do, R.K.; et al. Radioembolization as a Salvage Therapy for Heavily Pretreated Patients With Colorectal Cancer Liver Metastases: Factors That Affect Outcomes. Clin. Colorectal Cancer 2015, 14, 296-305. [CrossRef]

93. Kennedy, A.S.; Ball, D.; Cohen, S.J.; Cohn, M.; Coldwell, D.M.; Drooz, A.; Ehrenwald, E.; Kanani, S.; Rose, S.C.; Nutting, C.W.; et al. Multicenter evaluation of the safety and efficacy of radioembolization in patients with unresectable colorectal liver metastases selected as candidates for (90)Y resin microspheres. J. Gastrointest Oncol. 2015, 6, 134-142. [CrossRef] [PubMed]

94. Lewandowski, R.J.; Memon, K.; Mulcahy, M.F.; Hickey, R.; Marshall, K.; Williams, M.; Salzig, K.; Gates, V.L.; Atassi, B.; Vouche, M.; et al. Twelve-year experience of radioembolization for colorectal hepatic metastases in 214 patients: Survival by era and chemotherapy. Eur. J. Nucl. Med. Mol. Imaging 2014, 41, 1861-1869. [CrossRef] [PubMed]

95. Hickey, R.; Lewandowski, R.J.; Prudhomme, T.; Ehrenwald, E.; Baigorri, B.; Critchfield, J.; Kallini, J.; Gabr, A.; Gorodetski, B.; Geschwind, J.F.; et al. 90Y Radioembolization of Colorectal Hepatic Metastases Using Glass Microspheres: Safety and Survival Outcomes from a 531-Patient Multicenter Study. J. Nucl. Med. 2016, 57, 665-671. [CrossRef] [PubMed]

96. Mayer, R.J.; Van Cutsem, E.; Falcone, A.; Yoshino, T.; Garcia-Carbonero, R.; Mizunuma, N.; Yamazaki, K.; Shimada, Y.; Tabernero, J.; Komatsu, Y.; et al. Randomized trial of TAS-102 for refractory metastatic colorectal cancer. N. Engl. J. Med. 2015, 372, 1909-1919. [CrossRef]

97. Grothey, A.; Van Cutsem, E.; Sobrero, A.; Siena, S.; Falcone, A.; Ychou, M.; Humblet, Y.; Bouché, O.; Mineur, L.; Barone, C.; et al. Regorafenib monotherapy for previously treated metastatic colorectal cancer (CORRECT): An international, multicentre, randomised, placebo-controlled, phase 3 trial. Lancet 2013, 381, 303-312. [CrossRef]

98. Shady, W.; Kishore, S.; Gavane, S.; Do, R.K.; Osborne, J.R.; Ulaner, G.A.; Gonen, M.; Ziv, E.; Boas, F.E.; Sofocleous, C.T. Metabolic tumor volume and total lesion glycolysis on FDG-PET/CT can predict overall survival after (90)Y radioembolization of colorectal liver metastases: A comparison with SUVmax, SUVpeak, and RECIST 1.0. Eur. J. Radiol. 2016, 85, 1224-1231. [CrossRef]

99. Townsend, A.R.; Chong, L.C.; Karapetis, C.; Price, T.J. Selective internal radiation therapy for liver metastases from colorectal cancer. Cancer Treat. Rev. 2016, 50, 148-154. [CrossRef] [PubMed]

100. Van Hazel, G.; Blackwell, A.; Anderson, J.; Price, D.; Moroz, P.; Bower, G.; Cardaci, G.; Gray, B. Randomised phase 2 trial of SIR-Spheres plus fluorouracil/leucovorin chemotherapy versus fluorouracil/leucovorin chemotherapy alone in advanced colorectal cancer. J. Surg. Oncol. 2004, 88, 78-85. [CrossRef]

101. Wasan, H.S.; Gibbs, P.; Sharma, N.K.; Taieb, J.; Heinemann, V.; Ricke, J.; Peeters, M.; Findlay, M.; Weaver, A.; Mills, J.; et al. First-line selective internal radiotherapy plus chemotherapy versus chemotherapy alone in patients with liver metastases from colorectal cancer (FOXFIRE, SIRFLOX, and FOXFIRE-Global): A combined analysis of three multicentre, randomised, phase 3 trials. Lancet Oncol. 2017, 18, 1159-1171. [CrossRef]

102. Chauhan, N.; Mulcahy, M.F.; Salem, R.; Benson Iii, A.B.; Boucher, E.; Bukovcan, J.; Cosgrove, D.; Laframboise, C.; Lewandowski, R.J.; Master, F.; et al. TheraSphere Yttrium-90 Glass Microspheres Combined With Chemotherapy Versus Chemotherapy Alone in Second-Line Treatment of Patients With Metastatic Colorectal Carcinoma of the Liver: Protocol for the EPOCH Phase 3 Randomized Clinical Trial. JMIR Res. Protoc. 2019, 8, e11545. [CrossRef]

103. Damm, R.; Seidensticker, R.; Ulrich, G.; Breier, L.; Steffen, I.G.; Seidensticker, M.; Garlipp, B.; Mohnike, K.; Pech, M.; Amthauer, H.; et al. Y90 Radioembolization in chemo-refractory metastastic, liver dominant colorectal cancer patients: Outcome assessment applying a predictive scoring system. BMC Cancer 2016, 16, 509. [CrossRef]

104. Kurilova, I.; Beets-Tan, R.G.H.; Flynn, J.; Gönen, M.; Ulaner, G.; Petre, E.N.; Edward Boas, F.; Ziv, E.; Yarmohammadi, H.; Klompenhouwer, E.G.; et al. Factors Affecting Oncologic Outcomes of 90Y Radioembolization of Heavily Pre-Treated Patients With Colon Cancer Liver Metastases. Clin. Colorectal Cancer 2019, 18, 8-18. [CrossRef] [PubMed] 
105. Lahti, S.J.; Xing, M.; Zhang, D.; Lee, J.J.; Magnetta, M.J.; Kim, H.S. KRAS Status as an Independent Prognostic Factor for Survival after Yttrium-90 Radioembolization Therapy for Unresectable Colorectal Cancer Liver Metastases. J. Vasc. Interv. Radiol. 2015, 26, 1102-1111. [CrossRef]

106. Ziv, E.; Bergen, M.; Yarmohammadi, H.; Boas, F.E.; Petre, E.N.; Sofocleous, C.T.; Yaeger, R.; Solit, D.B.; Solomon, S.B.; Erinjeri, J.P. PI3K pathway mutations are associated with longer time to local progression after radioembolization of colorectal liver metastases. Oncotarget 2017, 8, 23529-23538. [CrossRef]

107. Dabrowiecki, A.; Sankhla, T.; Shinn, K.; Bercu, Z.L.; Ermentrout, M.; Shaib, W.; Cardona, K.; Newsome, J.; Kokabi, N. Impact of Genomic Mutation and Timing of Y90 Radioembolization in Colorectal Liver Metastases. Cardiovasc. Interv. Radiol. 2020, 43, 1006-1014. [CrossRef] [PubMed]

108. van Hazel, G.A.; Heinemann, V.; Sharma, N.K.; Findlay, M.P.; Ricke, J.; Peeters, M.; Perez, D.; Robinson, B.A.; Strickland, A.H.; Ferguson, T.; et al. SIRFLOX: Randomized Phase III Trial Comparing First-Line mFOLFOX6 (Plus or Minus Bevacizumab) Versus mFOLFOX6 (Plus or Minus Bevacizumab) Plus Selective Internal Radiation Therapy in Patients With Metastatic Colorectal Cancer. J. Clin. Oncol. 2016, 34, 1723-1731. [CrossRef]

109. Dutton, S.J.; Kenealy, N.; Love, S.B.; Wasan, H.S.; Sharma, R.A. FOXFIRE protocol: An open-label, randomised, phase III trial of 5-fluorouracil, oxaliplatin and folinic acid (OxMdG) with or without interventional Selective Internal Radiation Therapy (SIRT) as first-line treatment for patients with unresectable liver-only or liver-dominant metastatic colorectal cancer. BMC Cancer 2014, 14, 497. [CrossRef]

110. Sharma, R.A.; Wasan, H.S.; Love, S.B.; Dutton, S.; Stokes, J.C.; Smith, J.L. FOXFIRE: A phase III clinical trial of chemo-radioembolisation as first-line treatment of liver metastases in patients with colorectal cancer. Clin. Oncol. R Coll. Radiol. 2008, 20, 261-263. [CrossRef]

111. Braat, A.; Kappadath, S.C.; Bruijnen, R.C.G.; van den Hoven, A.F.; Mahvash, A.; de Jong, H.; Lam, M. Adequate SIRT activity dose is as important as adequate chemotherapy dose. Lancet Oncol. 2017, 18, e636. [CrossRef]

112. Gibbs, P.; Heinemann, V.; Sharma, N.K.; Taieb, J.; Ricke, J.; Peeters, M.; Findlay, M.; Robinson, B.; Jackson, C.; Strickland, A.; et al. Effect of Primary Tumor Side on Survival Outcomes in Untreated Patients With Metastatic Colorectal Cancer When Selective Internal Radiation Therapy Is Added to Chemotherapy: Combined Analysis of Two Randomized Controlled Studies. Clin. Colorectal Cancer 2018, 17, e617-e629. [CrossRef] [PubMed]

113. Petrelli, F.; Tomasello, G.; Borgonovo, K.; Ghidini, M.; Turati, L.; Dallera, P.; Passalacqua, R.; Sgroi, G.; Barni, S. Prognostic Survival Associated With Left-Sided vs Right-Sided Colon Cancer: A Systematic Review and Meta-analysis. JAMA Oncol. 2017, 3, 211-219. [CrossRef] [PubMed]

114. Stintzing, S.; Tejpar, S.; Gibbs, P.; Thiebach, L.; Lenz, H.J. Understanding the role of primary tumour localisation in colorectal cancer treatment and outcomes. Eur. J. Cancer 2017, 84, 69-80. [CrossRef]

115. Wolstenholme, J.; Fusco, F.; Gray, A.M.; Moschandreas, J.; Virdee, P.S.; Love, S.; Van Hazel, G.; Gibbs, P.; Wasan, H.S.; Sharma, R.A. Quality of life in the FOXFIRE, SIRFLOX and FOXFIRE-global randomised trials of selective internal radiotherapy for metastatic colorectal cancer. Int. J. Cancer 2020, 147, 1078-1085. [CrossRef] [PubMed]

116. Cucchetti, A.; Cappelli, A.; Ercolani, G.; Mosconi, C.; Cescon, M.; Golfieri, R.; Pinna, A.D. Selective Internal Radiation Therapy (SIRT) as Conversion Therapy for Unresectable Primary Liver Malignancies. Liver Cancer 2016, 5, 303-311. [CrossRef]

117. Jeyarajah, D.R.; Doyle, M.B.M.; Espat, N.J.; Hansen, P.D.; Iannitti, D.A.; Kim, J.; Thambi-Pillai, T.; Visser, B.C. Role of yttrium-90 selective internal radiation therapy in the treatment of liver-dominant metastatic colorectal cancer: An evidence-based expert consensus algorithm. J. Gastrointest Oncol. 2020, 11, 443-460. [CrossRef]

118. Hemming, A.W.; Reed, A.I.; Howard, R.J.; Fujita, S.; Hochwald, S.N.; Caridi, J.G.; Hawkins, I.F.; Vauthey, J.N. Preoperative portal vein embolization for extended hepatectomy. Ann. Surg. 2003, 237, 686-691; discussion 691-693. [CrossRef]

119. Vivarelli, M.; Vincenzi, P.; Montalti, R.; Fava, G.; Tavio, M.; Coletta, M.; Vecchi, A.; Nicolini, D.; Agostini, A.; Ahmed, E.A.; et al. ALPPS Procedure for Extended Liver Resections: A Single Centre Experience and a Systematic Review. PLoS ONE 2015, 10, e0144019. [CrossRef]

120. Gulec, S.A.; Pennington, K.; Hall, M.; Fong, Y. Preoperative Y-90 microsphere selective internal radiation treatment for tumor downsizing and future liver remnant recruitment: A novel approach to improving the safety of major hepatic resections. World $J$. Surg. Oncol. 2009, 7, 6. [CrossRef]

121. Siddiqi, N.H.; Devlin, P.M. Radiation lobectomy-a minimally invasive treatment model for liver cancer: Case report. J. Vasc. Interv. Radiol. JVIR 2009, 20, 664-669. [CrossRef]

122. Birgin, E.; Rasbach, E.; Seyfried, S.; Rathmann, N.; Diehl, S.J.; Schoenberg, S.O.; Reissfelder, C.; Rahbari, N.N. Contralateral Liver Hypertrophy and Oncological Outcome Following Radioembolization with (90)Y-Microspheres: A Systematic Review. Cancers Basel 2020, 12, 294. [CrossRef]

123. Garlipp, B.; Gibbs, P.; Van Hazel, G.A.; Jeyarajah, R.; Martin, R.C.G.; Bruns, C.J.; Lang, H.; Manas, D.M.; Ettorre, G.M.; Pardo, F.; et al. Secondary technical resectability of colorectal cancer liver metastases after chemotherapy with or without selective internal radiotherapy in the randomized SIRFLOX trial. Br. J. Surg. 2019, 106, 1837-1846. [CrossRef]

124. Ruers, T.; Van Coevorden, F.; Punt, C.J.; Pierie, J.E.; Borel-Rinkes, I.; Ledermann, J.A.; Poston, G.; Bechstein, W.; Lentz, M.A.; Mauer, M.; et al. Local Treatment of Unresectable Colorectal Liver Metastases: Results of a Randomized Phase II Trial. J. Natl. Cancer Inst. 2017, 109. [CrossRef] [PubMed] 
125. Riaz, A.; Gates, V.L.; Atassi, B.; Lewandowski, R.J.; Mulcahy, M.F.; Ryu, R.K.; Sato, K.T.; Baker, T.; Kulik, L.; Gupta, R.; et al. Radiation segmentectomy: A novel approach to increase safety and efficacy of radioembolization. Int. J. Radiat.Oncol. Biol. Phys. 2011, 79, 163-171. [CrossRef] [PubMed]

126. Vouche, M.; Habib, A.; Ward, T.J.; Kim, E.; Kulik, L.; Ganger, D.; Mulcahy, M.; Baker, T.; Abecassis, M.; Sato, K.T.; et al. Unresectable solitary hepatocellular carcinoma not amenable to radiofrequency ablation: Multicenter radiology-pathology correlation and survival of radiation segmentectomy. Hepatology 2014, 60, 192-201. [CrossRef]

127. Meiers, C.; Taylor, A.; Geller, B.; Toskich, B. Safety and initial efficacy of radiation segmentectomy for the treatment of hepatic metastases. J. Gastrointest Oncol. 2018, 9, 311-315. [CrossRef]

128. Kurilova, I.; Bendet, A.; Fung, E.K.; Petre, E.N.; Humm, J.L.; Boas, F.E.; Crane, C.H.; Kemeny, N.; Kingham, T.P.; Cercek, A.; et al. Radiation segmentectomy of hepatic metastases with Y-90 glass microspheres. Abdom. Radiol. N. Y. 2021. [CrossRef]

129. Riaz, A.; Awais, R.; Salem, R. Side effects of yttrium-90 radioembolization. Front. Oncol. 2014, 4, 198. [CrossRef] [PubMed]

130. Riaz, A.; Lewandowski, R.J.; Kulik, L.M.; Mulcahy, M.F.; Sato, K.T.; Ryu, R.K.; Omary, R.A.; Salem, R. Complications following radioembolization with yttrium-90 microspheres: A comprehensive literature review. J. Vasc. Interv. Radiol. 2009, 20, 1121-1130; quiz 1131. [CrossRef]

131. Zacharias, A.J.; Jayakrishnan, T.T.; Rajeev, R.; Rilling, W.S.; Thomas, J.P.; George, B.; Johnston, F.M.; Gamblin, T.C.; Turaga, K.K. Comparative Effectiveness of Hepatic Artery Based Therapies for Unresectable Colorectal Liver Metastases: A Meta-Analysis. PLoS ONE 2015, 10, e0139940. [CrossRef]

132. Levy, J.; Zuckerman, J.; Garfinkle, R.; Acuna, S.A.; Touchette, J.; Vanounou, T.; Pelletier, J.S. Intra-arterial therapies for unresectable and chemorefractory colorectal cancer liver metastases: A systematic review and meta-analysis. HPB Oxf. 2018, 20, 905-915. [CrossRef] [PubMed]

133. Dhir, M.; Zenati, M.S.; Jones, H.L.; Bartlett, D.L.; Choudry, M.H.A.; Pingpank, J.F.; Holtzman, M.P.; Bahary, N.; Hogg, M.E.; Zeh, H.J., III; et al. Effectiveness of Hepatic Artery Infusion (HAI) Versus Selective Internal Radiation Therapy (Y90) for Pretreated Isolated Unresectable Colorectal Liver Metastases (IU-CRCLM). Ann. Surg. Oncol. 2018, 25, 550-557. [CrossRef] [PubMed]

134. Cercek, A.; Gendel, V.; Jabbour, S.; Moore, D.; Chen, C.; Nosher, J.; Capanu, M.; Chou, J.F.; Boucher, T.; Kemeny, N.; et al. A Comparison of Yttrium-90 Microsphere Radioembolization to Hepatic Arterial Infusional Chemotherapy for Patients with Chemo-refractory Hepatic Colorectal Metastases. Curr. Treat. Options Oncol. 2017, 18, 42. [CrossRef] [PubMed] 